\title{
Adsorption of Glyoxal (CHOCHO) and Its UV Photolysis Products on the Surface of Atmospheric Ice Nanoparticles. DFT and Density Functional Tight-Binding Study
}

\author{
Stanislav K. Ignatov,,$^{\dagger \neq} \neq *$ Oleg B. Gadzhiev, ${ }^{\ddagger}$ Alexey G. Razuvaev, ${ }^{\ddagger}$ Artëm E. Masunov, ${ }^{\S}$ \\ and Otto Schrems ${ }^{\dagger, \perp}$
${ }^{\dagger}$ Alfred Wegener Institute, Helmholtz Centre for Polar and Marine Research, Postfach 120161, D-27515 Bremerhaven, Germany
${ }^{\ddagger}$ N.I. Lobachevsky State University of Nizhny Novgorod, 23 Gagarin Avenue, Nizhny Novgorod 603950, Russia
${ }^{\S}$ NanoScience Technology Center, Department of Chemistry and Department of Physics, University of Central Florida, 12424
Research Parkway, Ste 400, Orlando, Florida 32826, United States
${ }^{\perp}$ Department of Chemistry, University of Bremen, P.O. Box 330440, 28334 Bremen, Germany

\section{Supporting Information}

\begin{abstract}
The structures, energies, harmonic vibrational frequencies, and thermodynamic parameters of the water clusters $\left(\mathrm{H}_{2} \mathrm{O}\right)_{48},\left(\mathrm{H}_{2} \mathrm{O}\right)_{72}$, and $\left(\mathrm{H}_{2} \mathrm{O}\right)_{270}$ were calculated using the standard DFT theory $(\mathrm{BLYP} / 6-31++\mathrm{G}(\mathrm{d}, \mathrm{p})$ for small and medium clusters) and the modern tight-binding method SCC-DFTB (DFTBA and DFTB+). The adsorption and embedding of s-cis- and s-trans-glyoxal molecules as well as its sunlight UV photolysis products (molecules $\mathrm{CH}_{2} \mathrm{O}, \mathrm{HCOOH}, \mathrm{H}_{2} \mathrm{O}_{2}, \mathrm{CO}, \mathrm{CO}_{2}$ and radicals $\mathrm{CHO}, \mathrm{HO}, \mathrm{HO}_{2}$ ) on nanosized ice clusters of up to $2.5 \mathrm{~nm}$ in diameter were studied within the above theoretical models. The structures of adsorption complexes on different sites of ice nanoparticles, the corresponding adsorption energies and thermodynamic parameters were estimated. We found that the DFTB method is a very promising tool for the calculations of structures and energies of ice nanoparticles, when compared to both DFT and semiempirical (PM3) methods. The obtained results are discussed in relation to the possible photolysis pathways, the reaction rates in the gas phase and in the adsorbed state, and the mechanisms of glyoxal photolysis catalyzed by the ice nanoparticles in the Earth's atmosphere.
\end{abstract}

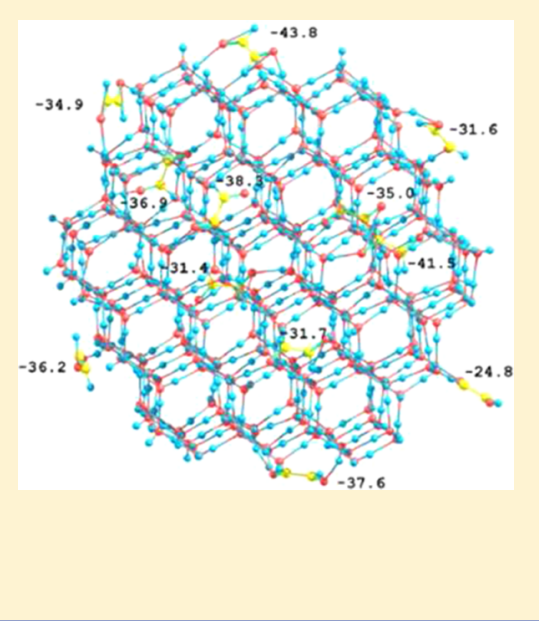

\section{INTRODUCTION}

Ice nanoparticles play an important role in physics and chemistry of the Earth atmosphere. ${ }^{1}$ Knowledge of the uptake and incorporation of atmospheric trace gases in ice particles as well as their interactions with water molecules is very important for the understanding of processes at the air/ice interface. The interaction of the atmospheric trace gases with atmospheric nanoparticles is also an important issue for the development of modern physicochemical models of the Earth atmosphere. These models, however, should take into account not only the mass balance of adsorbed species but also their possible photochemical transformations, as the trace gases trapped in snow, in ice particles or at ice surfaces may be subject of photochemical reactions when irradiated with solar $\mathrm{UV}$ radiation. $\mathrm{C}_{1}$ chemistry and reactivity of relatively small compounds $\left(\mathrm{CO}, \mathrm{CO}_{2}, \mathrm{H}, \mathrm{O}_{2}\right)$ in relation with the cosmic processes of organic matter formation were recently reviewed ${ }^{2}$ (see also ${ }^{3-6}$ ). Glyoxal is the simplest $\alpha$ dicarbonyl, an atmospheric relevant carbonyl compound. Its photodegradation, and interaction of the parent molecule and its photoproducts with atmospheric ice nanoparticles were the subject of several studies. Glyoxal is formed in the atmosphere through the photooxidation of simple volatile organic com- pounds in the presence of $\mathrm{NO}_{x}$. Measurements of glyoxal have been reported with mixing ratios ranging from $100 \mathrm{ppt}$ to a few ppb. Glyoxal has two main absorption bands on electronic absorption spectrum: a broad UV band between 220 and $350 \mathrm{~nm}$ and a stronger structured band in the $350-480 \mathrm{~nm}$ range. In the atmosphere, glyoxal is photolyzed by the sunlight. The gas-phase photolysis can occur through the following channels: ${ }^{7-17}$

$$
\begin{aligned}
& \mathrm{CHOCHO}+h \nu \rightarrow 2 \mathrm{HCO}\left(\lambda>417 \mathrm{~nm}, \Phi_{315 \mathrm{~nm}}\right. \\
& \left.\quad=0.75,^{8} \Phi_{308 \mathrm{~nm}}=0.4^{9}\right) \\
& \mathrm{CHOCHO}+h \nu \rightarrow \mathrm{H}_{2} \mathrm{CO}+\mathrm{CO}\left(\Phi_{308 \mathrm{~nm}}=0.45^{9}\right) \\
& \mathrm{CHOCHO}+h \nu \rightarrow \mathrm{H}_{2}+2 \mathrm{CO}\left(\Phi_{308 \mathrm{~nm}}=0.15^{9}\right) \\
& \mathrm{CHOCHO}+h \nu \rightarrow \mathrm{H}+\mathrm{CO}+\mathrm{HCO}\left(\lambda<334 \mathrm{~nm}^{10}\right)
\end{aligned}
$$

Because of secondary reactions occurring in the air, the main observed photolysis products are $\mathrm{CO}, \mathrm{CH}_{2} \mathrm{O}$, and $\mathrm{HCOOH}^{7}$ It

Received: November 23, 2013

Revised: March 18, 2014

Published: March 20, 2014 
(a)

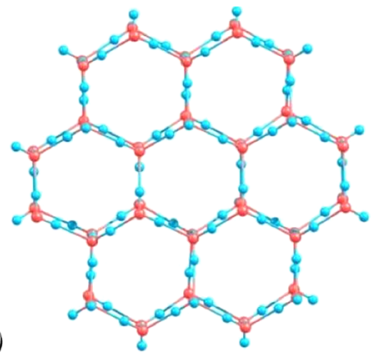

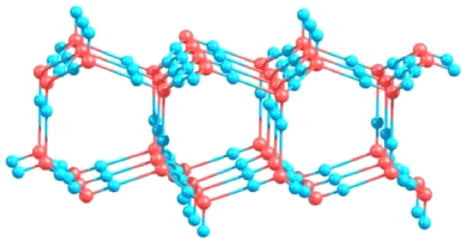

(b)

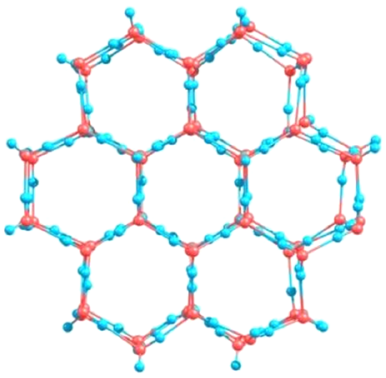

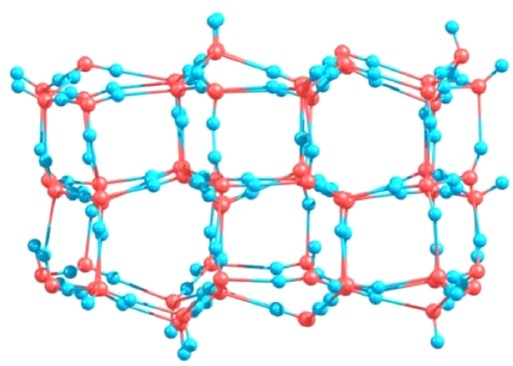

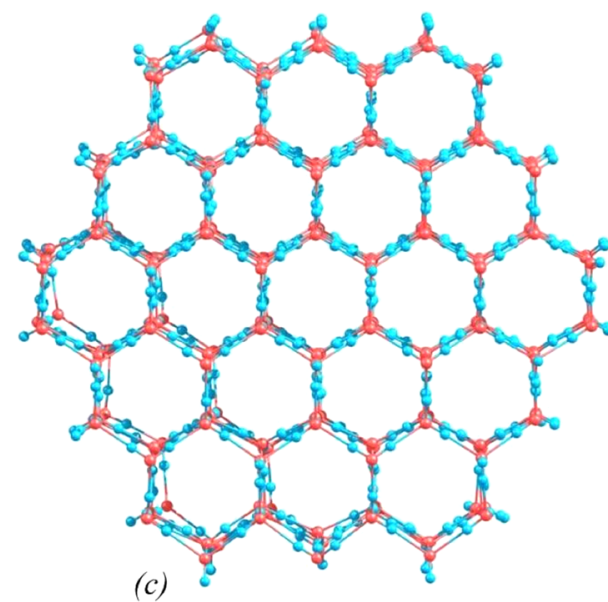

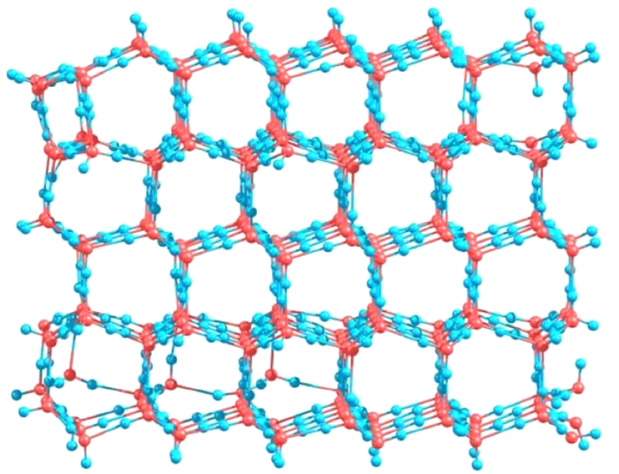

Figure 1. Optimized structures of source ice nanoparticles: (a) $\left(\mathrm{H}_{2} \mathrm{O}\right)_{48}$, BLYP/6-31++G(d,p) partial optimization with boundary O atoms fixed; (b) $\left(\mathrm{H}_{2} \mathrm{O}\right)_{72}, \mathrm{BLYP} / 6-31++\mathrm{G}(\mathrm{d}, \mathrm{p})$ full optimization; $(\mathrm{c})\left(\mathrm{H}_{2} \mathrm{O}\right)_{270}$, RI-BLYP/6-31+G(d,p) full optimization. Left panel: top view. Right panel: side view.

is obvious that the photolysis of glyoxal is also an important source of $\mathrm{CHO}$ radicals which can contribute to the formation of $\mathrm{HO}_{2}{ }^{18}$ and thus influence further atmospheric processes.

In sharp contrast with the gas phase conditions, only a few studies were focused on the photolysis of glyoxal in the condensed phase (aqueous solution or on the ice surface). ${ }^{19-22}$ Among them, the FTIR study ${ }^{19}$ of glyoxal photolysis products in ice and on the ice surface formed during the UV photolysis revealed the spectral signatures of the photolysis products. However, the laboratory studies carried out so far considered the glyoxal photolysis in the bulk ice or on the solid ice surface at very low temperatures. The physicochemical conditions in the Earth atmosphere are quite different and the adsorption occurs there mostly on the small ice particles of nanoscale size, rather than on the bulk ice surface. There the glyoxal photolysis can occur through different pathways and the ice nanoparticles can affect both the mechanism of photolytic decomposition and the distribution of the products between the ice and gas phases. Such an environment was not studied, either in field experiments or under laboratory conditions. Under these circumstances, the quantum chemical modeling can provide significant information on the processes which take place at the molecular level.
The main goal of the present paper is to study the adsorption of glyoxal molecules, and the products and intermediates of its UV photolysis on the surface of ice nanoparticles in order to assess the energies and thermodynamic parameters of adsorption and incorporation processes and to determine how the product distribution and/or glyoxal photolysis mechanisms on ice nanoparticles are different from the photolysis occurring in the gas phase. The vibrational frequencies of the adsorbed products and intermediates are also of interest, because these quantities can be directly compared to the experimentally observed IR spectra of glyoxal adsorbed on ice films and thus can be helpful in assigning the observed spectral features. On the other hand, the calculated vibrational frequencies and IR intensities can also help to identify photolysis intermediates. Additional goal of this paper is to estimate the performance of modern theoretical methods for calculations of large systems and compare the reliability of their predictions with those of standard DFT and semiempirical methods.

\section{COMPUTATIONAL DETAILS}

Nanoparticle Models. The glyoxal adsorption on ice nanoparticles has been modeled within the cluster approxima- 
tion. For this purpose, a series of clusters $\left(\mathrm{H}_{2} \mathrm{O}\right)_{n}(n=48,72,270$, and, for some calculations, $n=216)$ with the hexagonal ice-like oxygen lattice structure has been constructed as initial models similar to those used in our previous study of methylhydroperoxide adsorption on ice surface. ${ }^{23}$ The structure of the clusters was chosen to describe different sites and crystallographic faces of the ideal ice $I_{h}$ crystal. Figure 1 shows the clusters $\left(\mathrm{H}_{2} \mathrm{O}\right)_{48}$, $\left(\mathrm{H}_{2} \mathrm{O}\right)_{72}$, and $\left(\mathrm{H}_{2} \mathrm{O}\right)_{270}$ used in this work to assess the crystal environment effects.

The $\left(\mathrm{H}_{2} \mathrm{O}\right)_{48}$ cluster was chosen as a minimum model representing the structural features of the basal plane of ice crystal, and $\left(\mathrm{H}_{2} \mathrm{O}\right)_{72}$ is the extended model with the additional water bilayer. In order to model the nanosize ice particle, the extended cluster $\left(\mathrm{H}_{2} \mathrm{O}\right)_{270}$ of the similar shape was used. This size was selected based on the recent experiments demonstrated that the spontaneous crystallization of the water droplets $\left(\mathrm{H}_{2} \mathrm{O}\right)_{n}$ begins from $n=260-290 .^{24}$ This is in agreement with earlier experimental studies $^{25,26}$ where the onset of crystallinity was found to occur for 200-1000-mer clusters, and theoretical (up to 27000 molecules with TIP4P potential where clusters with 1000 molecules were studied more extensively) and spectroscopic survey (up to $10^{6}$ molecules) of water clusters ${ }^{27}$ where it was found no qualitative different spectroscopic signature for clusters larger than about 300 molecules. Thus, the cluster $\left(\mathrm{H}_{2} \mathrm{O}\right)_{270}$ used here is the representative model which possesses both the necessary size and the structure close to the structure of basal plane of the ideal ice crystal surface. The nanoparticle of such size should be mostly crystalline in a free state which makes our adsorption model more realistic.

The proton ordering in the model ice clusters deserves a special discussion. In the ice structure the two possible hydrogen positions are occupied randomly, which results in exponential growth of the number of proton ordered structures when the size of the cluster increases. The different structures have different adsorption abilities and different contributions into the average adsorption energy of the bulk ice. Recently, we estimated the differences in the adsorption affinity of the clusters with various proton ordering modeling the $\mathrm{H}_{2} \mathrm{O}_{2}$ adsorption on a variety of different proton-disordered structures of $\left(\mathrm{H}_{2} \mathrm{O}\right)_{11}$ cluster. $^{21}$ The results obtained at the $\mathrm{B} 3 \mathrm{LYP} / 6-31++(\mathrm{d}, \mathrm{p})$ level showed that the effect of different proton ordering on the $\mathrm{H}_{2} \mathrm{O}_{2}$ adsorption energy is not very pronounced, although noticeable. The differences in the adsorption energy is about $10-15 \%$ of the maximum value which is comparable or lower than the uncertainty of the quantum chemical method or the cluster approximation itself. Therefore, in this study, we used P-ordered ice model of Pisani. ${ }^{28,29}$ This model is simple for construction and calculation, provides the proper physical parameters both for slabs and clusters (e.g., dipole moment of the bulk ice is close to zero), and it was already successfully used previously in adsorption studies. ${ }^{30}$ This model is slightly different from model of nanocluters proposed by Buch, ${ }^{31}$ namely, cage-like structures on top-layer of cluster to compensate dipole moment. ${ }^{27,32}$

Shape of the largest ice cluster $\left(\mathrm{H}_{2} \mathrm{O}\right)_{270}$ is close to cylinder with about $2.3 \mathrm{~nm}$ in diameter and $1.5 \mathrm{~nm}$ in height. The glyoxal molecules were coordinated to different sites of the ice nanoparticles corresponding to different ice $I_{h}$ crystal planes:

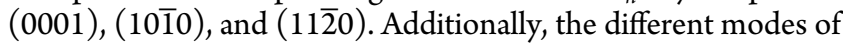
incorporation of the glyoxal molecules into the ice particles were considered and the corresponding structural and energetic parameters were evaluated. The structure of coordination complexes, their vibrational frequencies, the corresponding adsorption energies and thermodynamic parameters (the enthalpy and the Gibbs free energy of adsorption) were evaluated using the full optimization followed by the frequency calculations.

Theoretical Methods. The conventional density functional theory (DFT) and simplified tight-binding methods were used for the quantum chemical calculations of adsorption complexes structures, energies, vibrational frequencies, and thermodynamic parameters.

The DFT method (BLYP/6-31++G(d,p)) was used in the geometry optimizations with geometrical constraints (fixed boundary atoms) for the clusters $\left(\mathrm{H}_{2} \mathrm{O}\right)_{48}$ and their complexes $\left(\mathrm{H}_{2} \mathrm{O}\right)_{48} \mathrm{M}\left(\mathrm{M}=\mathrm{CO}, \mathrm{CO}_{2}, \mathrm{H}_{2} \mathrm{O}_{2}, \mathrm{H}_{2} \mathrm{CO}, \mathrm{HCO}\right.$, s-trans- or s-cisglyoxal, and s-trans- or s-cis- $\mathrm{HCOOH}$ ). Only most favorable conformer of $\mathrm{HCOOH}$ (s-cis- $\mathrm{HCOOH}$ ) was considered on $\left(\mathrm{H}_{2} \mathrm{O}\right)_{48}$ clusters in agreement with ref 33. For the $\left(\mathrm{H}_{2} \mathrm{O}\right)_{72}$ clusters and their complexes $\left(\mathrm{H}_{2} \mathrm{O}\right)_{72} \mathrm{M}_{2}$, the full geometry optimization was performed using the modern fast approach for resolution of identity (RI) for the DFT theory (RI-DFT) $)^{34,35}$ with standard and auxiliary basis sets as implemented in PRIRODA13 program. ${ }^{36-38}$ The validity of this theory level was additionally tested by the geometry optimization in the extended basis set (RI-BLYP/6-311++G $(2 \mathrm{~d}, 2 \mathrm{p})$ ) performed for the $\left(\mathrm{H}_{2} \mathrm{O}\right)_{72}$ cluster and the $\left(\mathrm{H}_{2} \mathrm{O}\right)_{72}(\mathrm{Gt})_{2}$ complex (here and later, $\mathrm{Gt}$ stands for s-trans-glyoxal). Vibrational spectra were calculated in the harmonic approximation on the structures optimized with BLYP/6-31++G(d,p) and RI-BLYP/6-31++G$(\mathrm{d}, \mathrm{p})$. In additional, we performed the optimization of the adsorption complexes of some molecules with the $\left(\mathrm{H}_{2} \mathrm{O}\right)_{270}$ cluster using the RI-BLYP/6-31++G(d,p)//RI-BLYP/6$31+\mathrm{G}(\mathrm{d})$ composite level of theory.

The modern theory of self-consistent charge density functional tight-binding model (SCC-DFTB, also known as a DFTB2 approach $^{39,40}$ ) in versions of SCC-DFTBA with fitted analytical forms $^{41}$ of DFTB parameters ${ }^{42}$ and SCC-DFTB with mio-1-1 set $^{42-45}$ of the tabulated Slater-Koster parameters were used. For short, we will reference these methods here as DFTBA and $\mathrm{DFTB}+$, respectively. The ice nanoparticles consisting of 48,72 , and 216 water molecules with a distorted structure of hexagonal water ice $I_{h}$ were studied using the DFTBA method combining the advantages of the DFT theory and semiempirical methods of quantum chemistry. The cluster $\left(\mathrm{H}_{2} \mathrm{O}\right)_{270}$ and its complexes were studied with the DFTB + method using its fast implementation realized in the DFTB+ software. ${ }^{46,47}$ The adsorption complexes of possible glyoxal photoproducts (radicals $\mathrm{HCO}, \mathrm{HO}$, and $\mathrm{HOO}$ ) were optimized with the collinear spin polarization approach ${ }^{48}$ for SCC-DFTB as implemented in the DFTB+ program. ${ }^{49}$

For the high-accuracy calculations of the reaction thermodynamics of possible photolytic processes and reactions of the photolysis products in the gas phase, the $\mathrm{G} 3^{50}$ method was applied as implemented in Gaussian09. For the high-accuracy calculations of small molecule structures and energies as well as for the search of transition states of the gas-phase elementary reactions of the glyoxal and its photoproduct in the gas phase, the $\operatorname{CCSD}(\mathrm{T})$ coupled-cluster method in conjunction with cc-pVTZ basis set was applied. For these calculations the CFOUR ${ }^{51}$ and Gaussian09 suites of programs were employed. Using these levels of theory, the transition states for the possible glyoxal and its photoproducts hydration were located and the influence of the water cluster surrounding on the barrier heights was studied.

All quantum chemical DFT and DFTBA calculations were performed with the Gaussian $03^{52}$ and Gaussian $09^{53}$ whereas the 
Table 1. G3 Calculated Energies and Thermodynamic and Activation Parameters (kJ mol ${ }^{-1}$ ) of Possible Reactions of the Glyoxal Photolysis in the Gas Phase

\begin{tabular}{|c|c|c|c|c|c|}
\hline reaction & $\Delta_{\mathrm{r}} E$ & $\Delta_{\mathrm{r}} H(0)\left(\Delta_{\mathrm{r}} E+\Delta_{\mathrm{r}} \mathrm{ZPE}\right)$ & $\Delta_{\mathrm{r}} H(298)$ & $\Delta_{\mathrm{r}} G(298)$ & $E_{a}$ \\
\hline \multicolumn{6}{|c|}{ Primary Reactions } \\
\hline$c-(\mathrm{HCO})_{2} \rightarrow 2 \mathrm{HCO}$ & 299.1 & 271.2 & 277.4 & 226.2 & $(299.1)^{a}$ \\
\hline$t-(\mathrm{HCO})_{2} \rightarrow 2 \mathrm{HCO}$ & 318.9 & 290.6 & 297.0 & 244.4 & $(318.9)^{a}$ \\
\hline \multicolumn{6}{|c|}{ Secondary Reactions } \\
\hline $2 \mathrm{HCO} \rightarrow \mathrm{CH}_{2} \mathrm{O}+\mathrm{CO}$ & -316.8 & -302.8 & -304.0 & -294.5 & $(38.0)^{b}$ \\
\hline $\mathrm{HCO}+\mathrm{H}_{2} \mathrm{O} \rightarrow \mathrm{HCOH}+\mathrm{HO}$ & 122.8 & 125.0 & 123.8 & 128.6 & 430.7 \\
\hline $\mathrm{HCO}+\mathrm{O}_{2} \rightarrow \mathrm{CO}+\mathrm{HOO}$ & -148.5 & -143.1 & -143.1 & -142.4 & - \\
\hline $2 \mathrm{HCO}+\mathrm{H}_{2} \mathrm{O} \rightarrow \mathrm{HCOOH}+\mathrm{CH}_{2} \mathrm{O}$ & -356.0 & -321.9 & -330.9 & -280.5 & - \\
\hline $2 \mathrm{HCO}+\mathrm{O}_{2} \rightarrow \mathrm{H}_{2} \mathrm{O}_{2}+2 \mathrm{CO}$ & -456.6 & -439.9 & -440.3 & -431.2 & - \\
\hline \multicolumn{6}{|c|}{ Tertiary Reactions } \\
\hline $\mathrm{HOO}+\mathrm{HCO} \rightarrow \mathrm{CH}_{2} \mathrm{O}+\mathrm{O}_{2}$ & -168.3 & -159.6 & -160.9 & -152.1 & - \\
\hline $\mathrm{HOO}+\mathrm{HCO} \rightarrow \mathrm{H}_{2} \mathrm{O}_{2}+\mathrm{CO}$ & -308.0 & -296.8 & -297.1 & -288.8 & - \\
\hline $\mathrm{HCOOH} \rightarrow \mathrm{CO}+\mathrm{H}_{2} \mathrm{O}$ & 39.1 & 19.2 & 26.9 & -14.0 & 541.9 \\
\hline $\mathrm{HCOOH} \rightarrow \mathrm{CO}_{2}+\mathrm{H}_{2}$ & 3.4 & -28.8 & -21.6 & -51.7 & 144.9 \\
\hline \multicolumn{6}{|c|}{ Summary Reactions } \\
\hline$t-(\mathrm{HCO})_{2} \rightarrow \mathrm{CH}_{2} \mathrm{O}+\mathrm{CO}$ & 2.1 & -12.2 & -7.1 & -50.1 & - \\
\hline$t-(\mathrm{HCO})_{2}+\mathrm{O}_{2} \rightarrow \mathrm{H}_{2} \mathrm{O}_{2}+2 \mathrm{CO}$ & -137.7 & -149.4 & -143.3 & -186.8 & - \\
\hline$t-(\mathrm{HCO})_{2}+\mathrm{H}_{2} \mathrm{O} \rightarrow \mathrm{CH}_{2} \mathrm{O}+\mathrm{HCOOH}$ & -37.1 & -31.4 & -34.0 & -36.1 & - \\
\hline$t-(\mathrm{HCO})_{2}+\mathrm{H}_{2} \mathrm{O} \rightarrow \mathrm{CH}_{2} \mathrm{O}+\mathrm{CO}_{2}+\mathrm{H}_{2}$ & -33.7 & -60.2 & -55.6 & -87.8 & - \\
\hline
\end{tabular}

${ }^{a}(\mathrm{HCO})_{2}$ dissociation energy. ${ }^{b}$ Multistep mechanism without the activation barrier above the reagents level. The indicated value is the activation energy for the rate-limiting step of the most favorable reaction channel $\left(\operatorname{CCSD}(\mathrm{T}, \mathrm{fc}) / \mathrm{cc}\right.$-pVTZ calculation $\left.{ }^{56}\right)$.

DFTB + software ${ }^{46,47}$ was used for the geometry optimization of largest clusters at the DFTB+ level. Original programs were used for the structure construction and selection. The MOLTRAN program $^{54}$ was applied for the input data preparation and output data analysis. The ChemCraft ${ }^{55}$ software was used for visualization and graphical data preparation.

\section{RESULTS}

Possible Products and Intermediates of the Glyoxal UV Photolysis on the Ice Nanoparticles. The first step of the gas phase photolysis of glyoxal molecule under the near UV irradiation is the formation of two CHO radicals: ${ }^{7-12,16,17}$

$$
(\mathrm{CHO})_{2} \rightarrow 2 \mathrm{CHO}
$$

The formed radicals undergo secondary reactions in the atmosphere including the bimolecular recombination, rearrangements and eliminations forming mostly $\mathrm{CH}_{2} \mathrm{O}, \mathrm{CO}$, and $\mathrm{CO}_{2}:{ }^{10}$

$$
\begin{aligned}
& 2 \mathrm{CHO} \rightarrow(\mathrm{CHO})_{2} \\
& \mathrm{CHO}+(\mathrm{CHO})_{2}+\mathrm{H}_{2} \mathrm{O}+\mathrm{O}_{2} \rightarrow \mathrm{CH}_{2} \mathrm{O}+\mathrm{CO}+\mathrm{CO}_{2} \\
& \quad+\cdots
\end{aligned}
$$

These products were also observed in the UV photolysis experiments of glyoxal deposited on ice films at $80-100 \mathrm{~K} .{ }^{19}$ The mechanisms of reactions 1 and 2 were thoroughly studied using different experimental approaches including the kinetic studies based on the cavity ring-down spectroscopy. ${ }^{10}$ The photochemical rates, quantum yields, and the dissociation/quenching ratios were studied in details with different wavelengths. ${ }^{11,12,16,17}$ The mechanism of the further transformations corresponding to the Scheme 3 was studied to a lesser extent. It was shown ${ }^{10}$ that the main channel proceeds to $\mathrm{CH}_{2} \mathrm{O}$ and $\mathrm{CO}$ mostly by abstraction of an $\mathrm{H}$ atom from the glyoxal molecule or the second CHO radical:

$$
\mathrm{CHO}+(\mathrm{CHO})_{2} \rightarrow \mathrm{CH}_{2} \mathrm{O}+\text { other products }
$$

$$
\mathrm{CHO}+\mathrm{CHO} \rightarrow \mathrm{CH}_{2} \mathrm{O}+\mathrm{CO}
$$

The occurrence of the first reaction is quite unlikely in the atmosphere where the concentration of glyoxal is extremely low. The second reaction can occur both in the gas phase and in the solid state cage of the ice. Earlier, we tried to model it using the $\operatorname{CCSD}(\mathrm{T})$ method. $^{56}$ However, this reaction has a rather complicated mechanism and details of this study will be presented elsewhere. The main conclusion from this modeling ${ }^{56}$ is that the reaction cannot occur through the single-step bimolecular formaldehyde formation. Instead, it includes the formation of hydroxycarbene $\mathrm{HCOH}$ that undergoes further reactions:

$$
\mathrm{OCH}+\mathrm{OCH} \rightarrow \mathrm{O}=\mathrm{C}+\mathrm{H}-\mathrm{C}-\mathrm{O}-\mathrm{H} \rightarrow \cdots
$$

Because the reaction on the surface of ice particles occurs in the presence of water molecules, it can involve hydrogen transfer steps, e.g.:

$$
\begin{aligned}
& \mathrm{CHO}+\mathrm{H}_{2} \mathrm{O} \rightarrow[\mathrm{CHO} \cdots \mathrm{H}-\mathrm{OH}] \rightarrow \mathrm{H}_{2} \mathrm{CO}+\mathrm{HO} \\
& 2 \mathrm{CHO}+\mathrm{H}_{2} \mathrm{O} \rightarrow \mathrm{HCOOH}+\mathrm{HCOH}
\end{aligned}
$$

Although the first reaction is unlikely due to the reaction endothermicity, the second reaction is more spontaneous. Recently, the water complexes of $\mathrm{CHO}$ radical was reported by the Räsanen group. ${ }^{57}$ In another study the hydrolysis of $\mathrm{HCOH}$ was considered in an environment of several water molecules. ${ }^{58}$ Although $\mathrm{HCOOH}$ was not identified ${ }^{19}$ during the photolysis of glyoxal on the ice films, this can be due to the fast secondary photodecomposition of $\mathrm{HCOOH}$ under UV irradiation with formation of $\mathrm{CO}$ and $\mathrm{CO}_{2}$ :

$$
\begin{aligned}
& \mathrm{HCOOH} \rightarrow \mathrm{CO}+\mathrm{H}_{2} \mathrm{O} \\
& \mathrm{HCOOH} \rightarrow \mathrm{CO}_{2}+\mathrm{H}_{2}
\end{aligned}
$$

One cannot also rule out, that the photolysis can involve the steps of $\mathrm{HOO}$ radical and $\mathrm{H}_{2} \mathrm{O}_{2}$ formation occurring when free 
Table 2. Adsorption Energies $\left(\mathrm{kJ} \mathrm{mol}^{-1}\right)$ of Glyoxal Photolysis Products Calculated at the DFT and DFTBA Levels for the Different Nanoparticle Models (Coordination at the (0001) Plane)

\begin{tabular}{|c|c|c|c|c|}
\hline & $\mathrm{BLYP} / 6-31++\mathrm{G}(\mathrm{d}, \mathrm{p})$ & RI-BLYP/6-31++G(d,p) & \multicolumn{2}{|c|}{ DFTBA } \\
\hline & $\left(\mathrm{H}_{2} \mathrm{O}\right)_{48}^{a}$ & $\left(\mathrm{H}_{2} \mathrm{O}\right)_{72}$ & $\left(\mathrm{H}_{2} \mathrm{O}\right)_{48}{ }^{a}$ & $\left(\mathrm{H}_{2} \mathrm{O}\right)_{72}$ \\
\hline$s$-cis- $(\mathrm{CHO})_{2}$ & -43.5 & -44.2 & -38.8 & $-41.9(-40.2)^{b}$ \\
\hline$s$-trans- $(\mathrm{CHO})_{2}$ & -19.8 & -33.9 & -22.7 & $-28.6(-33.0)^{b}$ \\
\hline $\mathrm{CH}_{2} \mathrm{O}$ & -29.2 & -35.0 & -20.1 & -22.0 \\
\hline$s$-cis-HCOOH & -57.5 & -37.3 & -47.1 & -38.4 \\
\hline $\mathrm{H}_{2} \mathrm{O}_{2}$ & -53.2 & -48.0 & -30.4 & -39.3 \\
\hline $\mathrm{CO}(\mathrm{O}-\mathrm{H} \cdots \mathrm{CO}$ contact $)$ & -8.8 & $-16.9(-9.8)^{c}$ & -3.1 & -3.2 \\
\hline $\mathrm{CO}(\mathrm{O}-\mathrm{H} \cdots \mathrm{OC}$ contact $)$ & -4.6 & $-10.6(-4.1)^{c}$ & -3.7 & -4.2 \\
\hline $\mathrm{CO}_{2}$ & -8.8 & -20.9 & -12.6 & -15.0 \\
\hline $\mathrm{CHO}$ & -24.0 & -29.4 & & \\
\hline
\end{tabular}

${ }^{a}$ Partial optimization with fixed boundary atoms of bottom and side planes. ${ }^{b}$ Values obtained at the same theory level for $\left(\mathrm{H}_{2} \mathrm{O}\right)_{216}$ cluster (coordination on the (0001) plane). ${ }^{c}$ Values obtained for the same model at the BLYP/6-31++G(d,p) level with pruned grid (grid $=$ sglgrid in Gaussian09).
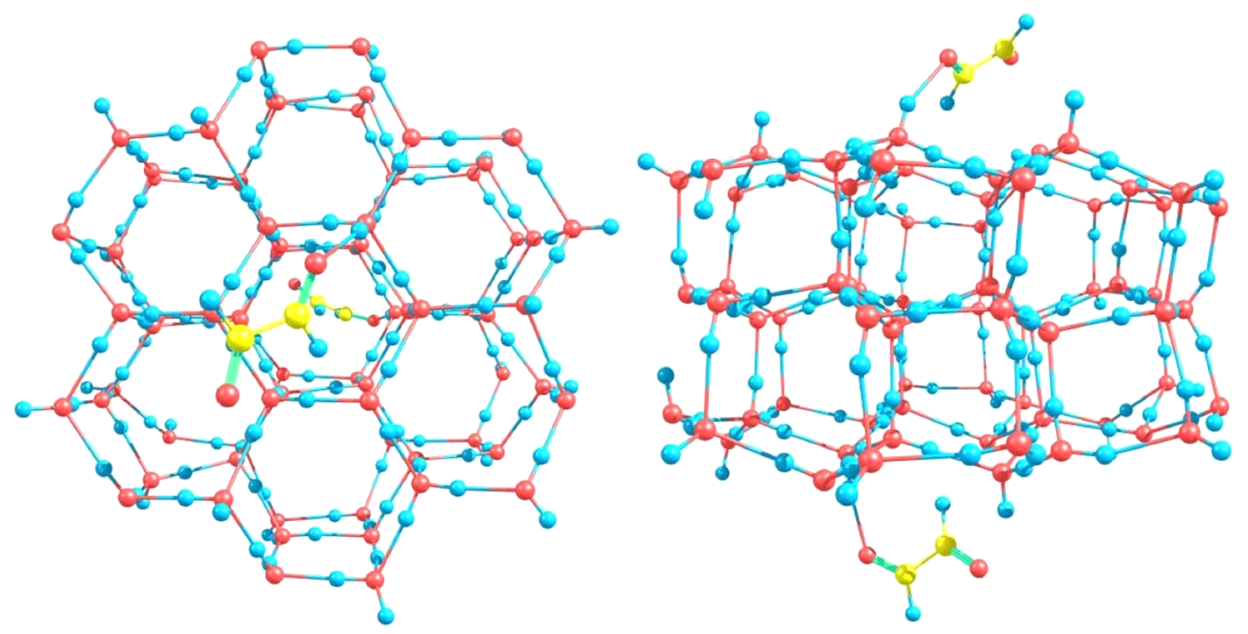

Figure 2. Optimized structure of two molecules s-trans-glyoxal complex on the basal plane of the $\left(\mathrm{H}_{2} \mathrm{O}\right)_{72}$ cluster, $\mathrm{BLYP} / 6-311++\mathrm{G}(2 \mathrm{~d}, 2 \mathrm{p})$ full optimization. Left panel: top view. Right panel: side view.

dioxygen molecules are present under atmospheric conditions. The possible reactions are

$$
\begin{aligned}
& \mathrm{CHO}+\mathrm{O}_{2} \rightarrow \mathrm{CO}+\mathrm{HOO} \\
& 2 \mathrm{CHO}+\mathrm{O}_{2} \rightarrow \mathrm{H}_{2} \mathrm{O}_{2}+2 \mathrm{CO} \\
& \mathrm{HOO}+\mathrm{CHO} \rightarrow \mathrm{H}_{2} \mathrm{O}_{2}+\mathrm{CO}
\end{aligned}
$$

Although photochemical reactions take place on the excited state potential energy surface, their computational study is rather involved, ${ }^{59,60}$ and for some steps activation berries on the ground state can suffice. ${ }^{61-63}$ In order to estimate the probability of the reaction steps above, we calculated the energies and thermodynamic parameters for these reaction steps. The results of the calculation are given in Table 1 . This table also includes the activation energies of the above steps obtained previously with the $\operatorname{CCSD}(\mathrm{T})$ method $^{56}$ or taken from another study. ${ }^{64,65}$

The data shown in the Table 1 allow one to conclude that all the proposed steps are possible under the UV photolysis. Among them, the most favorable products and intermediates involved in the photolysis process are $\mathrm{CH}_{2} \mathrm{O}$, and $\mathrm{CO}$. The molecules $\mathrm{CO}_{2}$, $\mathrm{HCOOH}, \mathrm{H}_{2} \mathrm{O}_{2}$ as well as the radicals $\mathrm{CHO}, \mathrm{HOO}, \mathrm{HO}$ can also be present in the reaction mixture in the adsorbed or embedded state in the ice nanoparticles. Below, we estimate the thermodynamic parameters of adsorption for all the most probable photoproducts.
Adsorption on Small-Size Model Ice Clusters. Adsorption parameters of the glyoxal and its photoproducts at the nanoparticles were studied using the models for ice surfaces described above. First, we calculated the structures of adsorption complexes for small clusters $\left(\mathrm{H}_{2} \mathrm{O}\right)_{48}$ and $\left(\mathrm{H}_{2} \mathrm{O}\right)_{72}$ at two different theory levels, BLYP/6-31++G(d,p) and DFTBA. The results are shown in Table 2. Adsorption complex for the $\left(\mathrm{H}_{2} \mathrm{O}\right)_{72}$ cluster and two glyoxal molecules is depicted in Figure 2.

As follows from Table 2, the adsorption energies for two cluster models differ rather significantly, sometimes up to almost $50 \%$ (s-trans-glyoxal, $\mathrm{HCOOH}$ ) and up to $100 \%$ (although only up to $10 \mathrm{~kJ} \mathrm{~mol}^{-1}$ in absolute values) for small molecules (CO, $\mathrm{CO}_{2}$ ). These significant differences between two cluster models are predicted at both DFT and DFTBA levels. At the same time, the difference between DFT and DFTBA results for larger clusters $\left(\mathrm{H}_{2} \mathrm{O}\right)_{72}$ are less pronounced. The only significant discrepancy takes place for the CO adsorption when the DFTBA method provides slightly higher negative adsorption energy. The discrepancies are also pronounced for the $\mathrm{CH}_{2} \mathrm{O}$ and $\mathrm{CO}_{2}$ adsorption since the DFTBA results are $5-15 \mathrm{~kJ} \mathrm{~mol}^{-1}$ lower in absolute values. For the larger cluster we also estimated the adsorption affinity regarding to the $\mathrm{CHO}$ radical. The $\mathrm{CHO}$ adsorption energy on the (0001) ice plane estimated at the DFT level in the structure optimization of the $\left(\mathrm{H}_{2} \mathrm{O}\right)_{72}(\mathrm{CHO})$ 
complex was $-29.4 \mathrm{~kJ} \mathrm{~mol}^{-1}$ (Table 2). This value is quite close to the adsorption energies of s-trans-glyoxal and $\mathrm{CH}_{2} \mathrm{O}$ in the same model. The difference between the adsorption energies of s-cis- and s-trans-glyoxal is almost equal to the energy difference between these conformers (Table 2).

In order to find out which cluster model is more reliable, we extended the cluster in size to $\left(\mathrm{H}_{2} \mathrm{O}\right)_{216}$ keeping the structure of the adsorption center similar to that used in smaller cluster models (the $\left(\mathrm{H}_{2} \mathrm{O}\right)_{216}$ cluster is a slab of three water bilayers similar to $\left(\mathrm{H}_{2} \mathrm{O}\right)_{72}$ but with larger diameter). The adsorption energies obtained at the DFTBA level for the s-cis- and s-transglyoxal (shown in Table 2 in parentheses) were much closer to the results of the $\left(\mathrm{H}_{2} \mathrm{O}\right)_{72}$ model (differ only by $2-5 \mathrm{~kJ} \mathrm{~mol}^{-1}$ from this cluster). Thus, one can make two main conclusions from these results. First, the results for the small cluster $\left(\mathrm{H}_{2} \mathrm{O}\right)_{48}$ are not reliable enough to describe the properties of the large nanosized particles. This cluster size effect on the energy of intermolecular interactions is known as nonadditivity ${ }^{66,67}$ (cooperativity). Second, the results obtained at the DFT and DFTB levels are rather close to each another and, thus, we can use the more efficient DFTBA method for the property evaluation of larger clusters.

Because the $\left(\mathrm{H}_{2} \mathrm{O}\right)_{72}$ cluster was the largest system where the GGA-RI-DFT calculations were still feasible in conjunction with the moderate basis set, we performed the calculations of the vibrational frequencies and evaluated the thermodynamic parameters of the (0001) adsorption for the glyoxal photoproducts at the BLYP/6-31++G(d,p) level. We also performed these calculation with larger basis set (BLYP/6-311++G(2d,2p)) for the adsorption of s-trans-glyoxal. For both theory levels we estimated the basis set superposition error (BSSE) using the standard Boys counterpoise technique. ${ }^{68}$ The results of these calculations are shown in Table 3 . The thermodynamic parameters are obtained at four different temperatures: 0,100 , 200 , and $298.15 \mathrm{~K}$ in order to model the conditions of deposition on the ice film prepared in the laboratory experiments, on the ice nanoparticles, and for the standard conditions, respectively.

Comparison of the results obtained in $6-31++G(d, p)$ and 6$311++G(2 d, 2 p)$ bases shows that the influence of basis set extension and BSSE correction (better accounted in larger basis) is substantial (Table 3). The basis set extension gives approximately $7 \mathrm{~kJ} \mathrm{~mol}^{-1}$ for the energies and enthalpies of strans-glyoxal and this difference is reduced only to $6 \mathrm{~kJ} \mathrm{~mol}^{-1}$ after the BSSE assessment. We conclude that the discrepancy 6$7 \mathrm{~kJ} \mathrm{~mol}^{-1}$ between the $\Delta E+\mathrm{BSSE}$ values obtained at BLYP/6$31++G(d, p)$ and BLYP/6-311++G $(2 d, 2 p)$ levels is the additive systematic error which should be accounted when the thermodynamic parameters of adsorption calculated at the $\mathrm{BLYP} / 6-31++\mathrm{G}(\mathrm{d}, \mathrm{p})$ level are considered. At the same time, the differences between the zero-point corrections calculated at two levels of theory are not so pronounced. The temperature dependence of adsorption enthalpies is also not significant and the enthalpy values change in range $2-4 \mathrm{~kJ} \mathrm{~mol}^{-1}$ regarding to the $\Delta H(0)$ value which is lower than the influence of the basis set extension (15.9 kJ mol ${ }^{-1}$ for s-trans-glyoxal). We conclude that the best estimate for the adsorption enthalpy for the s-transglyoxal in a broad range of temperatures is about $-18 \mathrm{~kJ} \mathrm{~mol}^{-1}$. As it is evident from the comparison of the Gibbs free energies, the entropy contribution amplifies the discrepancy between two theory levels to $9-12 \mathrm{~kJ} \mathrm{~mol}^{-1}$ (growing when the temperature increases). It is interesting that the adsorption energy of $s$-cisglyoxal is significantly higher than for the s-trans-conformer. This is probably due to the fact that the s-cis-conformation of this

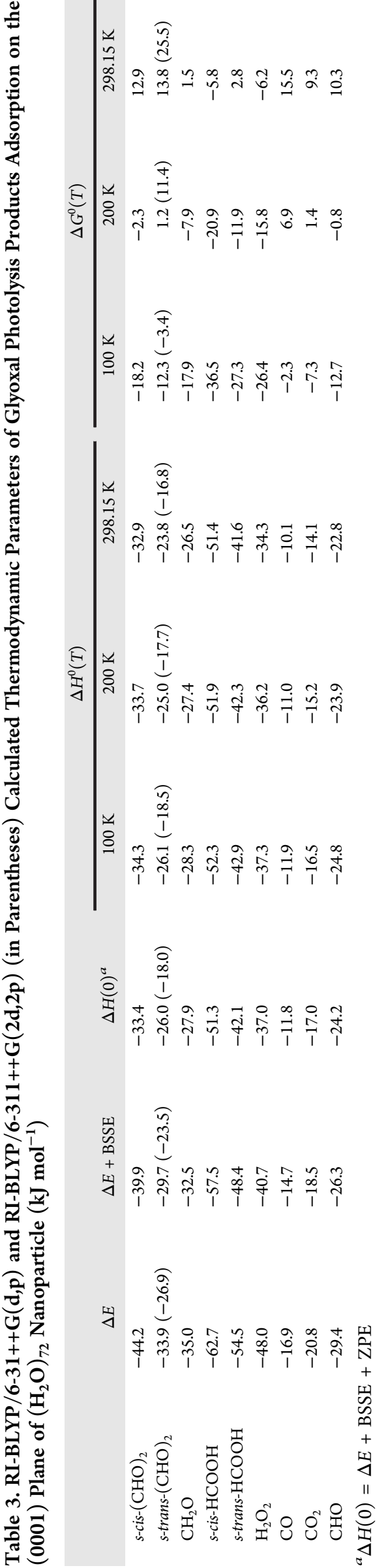



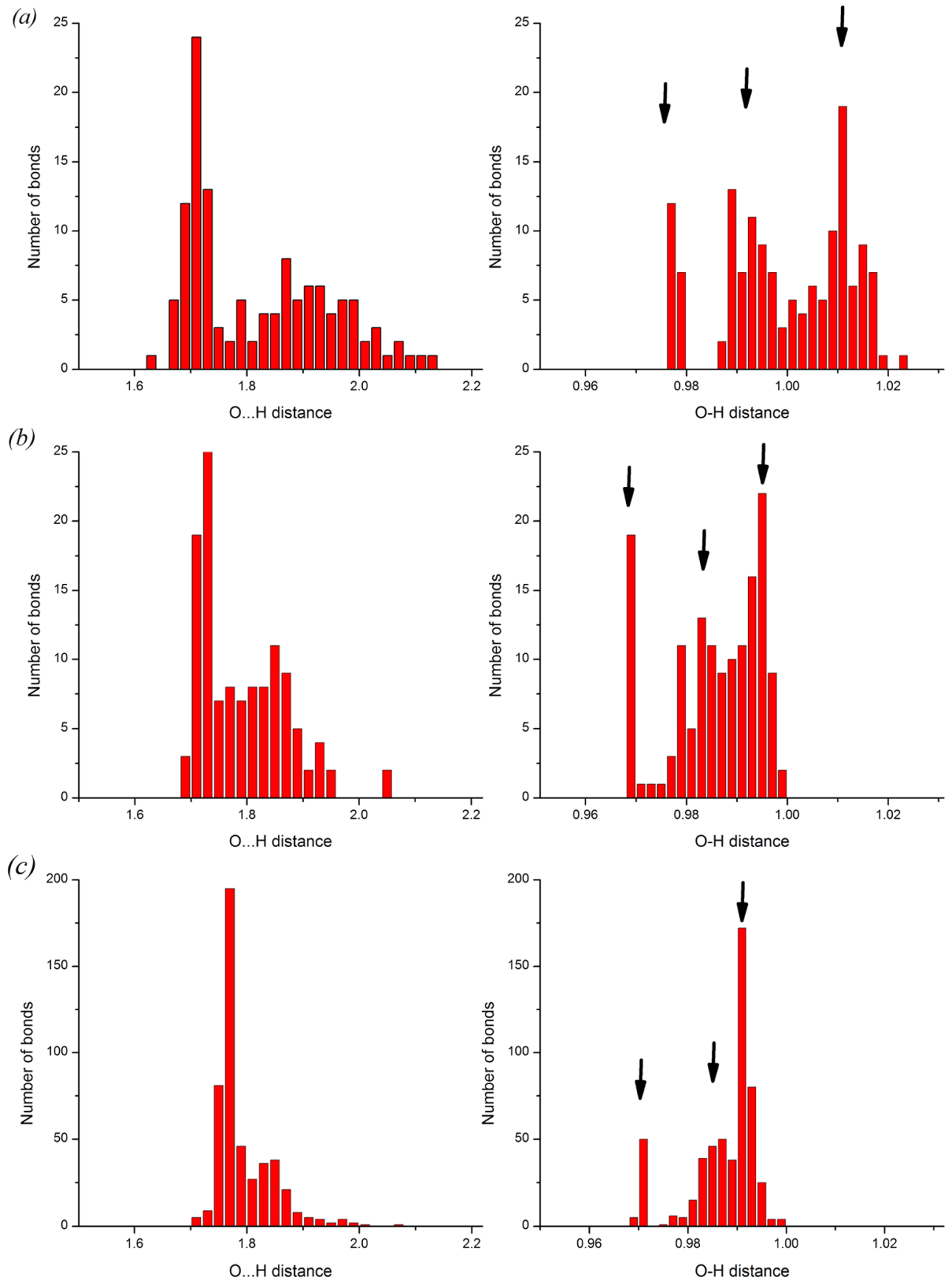

Figure 3. Calculated bond lengths distribution for the $\mathrm{O} \cdots \mathrm{H}$ (left panels) and $\mathrm{O}-\mathrm{H}$ (right panels) bonds in the optimized structures of ice nanoclusters: (a) $\left(\mathrm{H}_{2} \mathrm{O}\right)_{72}, \mathrm{BLYP} / 6-31++\mathrm{G}(\mathrm{d}, \mathrm{p})$; (b) $\left(\mathrm{H}_{2} \mathrm{O}\right)_{72}$, DFTB+; (c) $\left(\mathrm{H}_{2} \mathrm{O}\right)_{270}$, DFTB+. Bond lengths are in A.

molecule is more suitable for the bridge-like coordination which is more energetically favorable.

Structural Features of Ice Nanoparticles. The good performance of DFTBA method (in comparison with the DFT results) for the small- and medium-size ice clusters encourages the application of SCC-DFTB to the real-size ice nanoparticles. In this study, we applied the DFTB+ method (similar to DFTBA) to the ice cluster $\left(\mathrm{H}_{2} \mathrm{O}\right)_{270}$, as the original program ${ }^{46,47}$ is well suited for the large systems optimizations.

The full optimization of $\left(\mathrm{H}_{2} \mathrm{O}\right)_{270}$ at the DFTB+ theory level demonstrates some remarkable features of the geometry structure of the ice nanoparticle. First, the initial shape of the particle and the ice lattice is conserved in a course of optimization. Then, in the optimized structure, there are several rather different kinds of $\mathrm{O}-\mathrm{H}$ and $\mathrm{O} \cdots \mathrm{H}$ bonds distinguished by their length. This can be seen from Figure 3 where the histogram of $\mathrm{O}-\mathrm{H}$ and $\mathrm{O} \cdots \mathrm{H}$ bond lengths are shown. This is also seen from Table 4 where the statistical data for the bond lengths in clusters $\left(\mathrm{H}_{2} \mathrm{O}\right)_{72}$ and $\left(\mathrm{H}_{2} \mathrm{O}\right)_{270}$ are listed from DFT and DFTB+ calculations. The histogram of $\mathrm{O}-\mathrm{H}$ bond lengths has three main peaks corresponding to the shortened, normal and elongated bonds.

As follows from Table 4 the internal bond lengths in $\left(\mathrm{H}_{2} \mathrm{O}\right)_{270}$ (DFTB+ calculations) are $0.9920 \AA$ whereas the dangling bonds are significantly shortened $(0.9707 \AA)$ in contrast with the surface $\mathrm{O}-\mathrm{H}$ bonds $(0.9845 \AA)$. At the same time, the internal $\mathrm{O} \cdots \mathrm{H}$ bonds are significantly elongated $(1.86 \AA)$ in contrast with the average $\mathrm{O} \cdots \mathrm{H}$ lengths of $1.79 \AA$, and with the surface $\mathrm{O} \cdots \mathrm{H}$ 
Table 4. Bond Lengths Distribution in Clusters $\left(\mathrm{H}_{2} \mathrm{O}\right)_{72}$ and $\left(\mathrm{H}_{2} \mathrm{O}\right)_{270}$ Fully Optimized at the RI-BLYP/6-31++G(d,p), RI-BLYP/ 6-311++G(2d,2p), DFTB+, and PM3 levels $(\AA)$

\begin{tabular}{|c|c|c|c|c|c|}
\hline bond type & number of bonds & minimum value & maximum value & mean value & standard deviation \\
\hline \multicolumn{6}{|c|}{$\left(\mathrm{H}_{2} \mathrm{O}\right)_{72} / \mathrm{BLYP} / 6-31++\mathrm{G}(\mathrm{d}, \mathrm{p})(\mathrm{BLYP} / 6-311++\mathrm{G}(2 \mathrm{~d}, 2 \mathrm{p}))$} \\
\hline all $\mathrm{O}-\mathrm{H}$ & $144(144)$ & $0.9767(0.9710)$ & $1.0236(1.0258)$ & $0.9997(0.9923)$ & $0.0125(0.0122)$ \\
\hline dangling $\mathrm{O}-\mathrm{H}$ & $19(21)$ & $0.9767(0.9710)$ & $0.9782(0.9727)$ & $0.9777(0.9721)$ & $0.0004(0.0005)$ \\
\hline surface $\mathrm{O}-\mathrm{H}$ & $51(50)$ & $0.9863(0.9779)$ & $0.9984(0.9929)$ & $0.9927(0.9858)$ & $0.0033(0.0035)$ \\
\hline internal $\mathrm{O}-\mathrm{H}^{a}$ & $74(73)$ & $0.9997(0.9937)$ & $1.0236(1.0258)$ & $1.0101(1.0025)$ & $0.0051(0.0057)$ \\
\hline all $\mathrm{O} \cdots \mathrm{H}$ & $125(123)$ & $1.6247(1.5862)$ & $2.1248(2.2236)$ & $1.8197(1.8220)$ & $0.1238(0.1223)$ \\
\hline surface $\mathrm{O} \cdots \mathrm{H}^{b}$ & $66(71)$ & $1.6247(1.5862)$ & $1.8081(1.8243)$ & $1.7166(1.7325)$ & $0.0343(0.0442)$ \\
\hline internal $\mathrm{O} \cdots \mathrm{H}^{a}$ & $59(52)$ & $1.8111(1.8369)$ & $2.1248(2.2236)$ & $1.9350(1.9443)$ & $0.0764(0.0819)$ \\
\hline \multicolumn{6}{|c|}{$\left(\mathrm{H}_{2} \mathrm{O}\right)_{72} /$ DFTB $+($ PM3 $)$} \\
\hline all $\mathrm{O}-\mathrm{H}$ & $144(144)$ & $0.9686(0.9509)$ & $0.9995(0.9692)$ & $0.9860(0.9624)$ & $0.0089(0.0052)$ \\
\hline dangling $\mathrm{O}-\mathrm{H}$ & $19(27)$ & $0.9686(0.9509)$ & $0.9699(0.9537)$ & $0.9693(0.9522)$ & $0.0004(0.0007)$ \\
\hline surface $\mathrm{O}-\mathrm{H}$ & 51 & 0.9717 & 0.9869 & 0.9818 & 0.0036 \\
\hline internal $\mathrm{O}-\mathrm{H}^{a}$ & $74(117)^{c}$ & $0.9871(0.9609)^{c}$ & $0.9995(0.9692)^{c}$ & $0.9931(0.9647)^{c}$ & $0.0030(0.0020)^{c}$ \\
\hline all $\mathrm{O} \cdots \mathrm{H}$ & $125(117)$ & $1.6895(1.7520)$ & $2.2896(1.8149)$ & $1.7950(1.7812)$ & $0.0885(0.0148)$ \\
\hline internal $\mathrm{O} \cdots \mathrm{H}^{a}$ & $69(68)$ & $1.6895(1.7520)$ & $1.7855(1.7822)$ & $1.7331(1.7701)$ & $0.0222(0.0070)$ \\
\hline surface $\mathrm{O} \cdots \mathrm{H}^{b}$ & $56(49)$ & $1.7936(1.7850)$ & $2.2896(1.8149)$ & $1.8714(1.7965)$ & $0.0794(0.0068)$ \\
\hline \multicolumn{6}{|c|}{$\left(\mathrm{H}_{2} \mathrm{O}\right)_{270} /$ DFTB +} \\
\hline all $\mathrm{O}-\mathrm{H}$ & 540 & 0.9696 & 0.9999 & 0.9874 & 0.0069 \\
\hline dangling $\mathrm{O}-\mathrm{H}$ & 55 & 0.9696 & 0.9713 & 0.9707 & 0.0004 \\
\hline surface $\mathrm{O}-\mathrm{H}$ & 172 & 0.9752 & 0.9885 & 0.9845 & 0.0028 \\
\hline internal $\mathrm{O}-\mathrm{H}^{a}$ & 313 & 0.9886 & 0.9999 & 0.9920 & 0.0016 \\
\hline all $\mathrm{O} \cdots \mathrm{H}$ & 485 & 1.7005 & 2.0660 & 1.7936 & 0.0497 \\
\hline internal $\mathrm{O} \cdots \mathrm{H}^{a}$ & 342 & 1.7005 & 1.8049 & 1.7668 & 0.0156 \\
\hline surface $\mathrm{O} \cdots \mathrm{H}^{b}$ & 143 & 1.8079 & 2.0066 & 1.8575 & 0.0449 \\
\hline
\end{tabular}

${ }^{a}$ Mostly internal bonds with some surface ones. ${ }^{b}$ Mostly surface bonds on both basal and lateral planes. ${ }^{c}$ There is no clear difference between the internal and surface $\mathrm{O}-\mathrm{H}$ bond lengths at the PM3 level.

contacts of $1.77 \AA$. It is interesting that the elongated $\mathrm{O}-\mathrm{H}$ and shortened $\mathrm{O} \cdots \mathrm{H}$ bonds predominantly form the upper layer of $\mathrm{H}$-bonds. The second and deeper layers have the bond lengths sufficiently close to the averaged values. This is well seen in Figure 4 where the dangling $\mathrm{O}-\mathrm{H}$, surface $\mathrm{O}-\mathrm{H}$, surface $\mathrm{O} \cdots \mathrm{H}$, and internal $\mathrm{O} \cdots \mathrm{H}$ are marked with different colors (internal $\mathrm{O}-$ $\mathrm{H}$ are not shown). As it is evident from the Figure 4 the

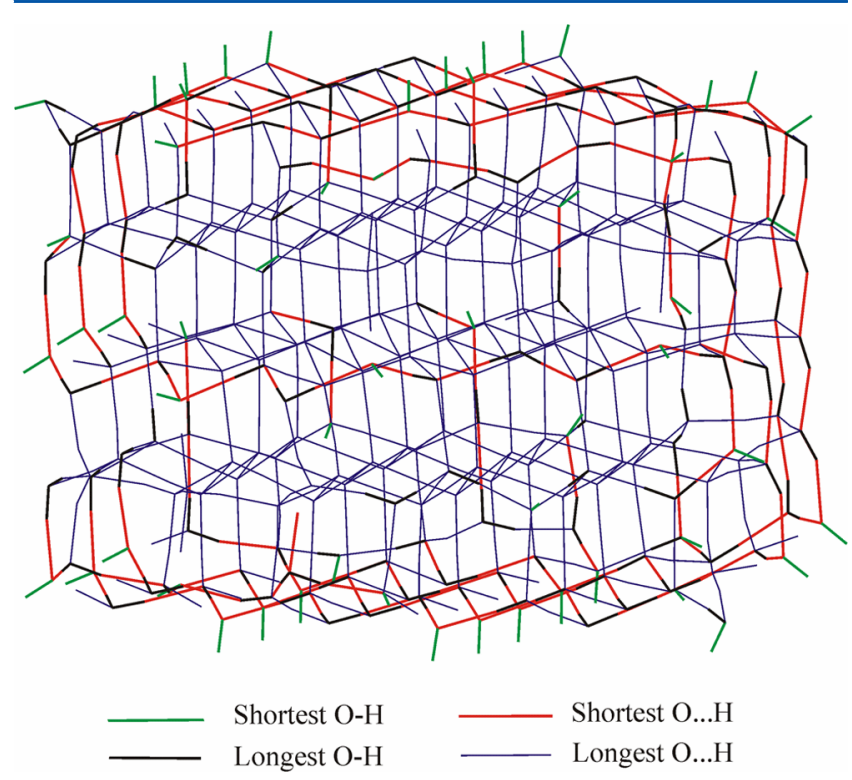

Figure 4. Different types of bonds in the cluster $\left(\mathrm{H}_{2} \mathrm{O}\right)_{270}$ as calculated at the DFTB+ level. See Table 4 for structural characteristics of different bond types. shortened $\mathrm{O} \cdots \mathrm{H}$ bonds constitute the external layer of hydrogen bonds mostly located on basal and two opposite side planes of the ice nanoparticle.

Glyoxal and Its Photoproducts on/in the Atmospheric Ice Nanoparticles. Using the cluster $\left(\mathrm{H}_{2} \mathrm{O}\right)_{270}$, several modes of the surface adsorption can be studied. In order to make the calculation faster, we considered these modes in a single calculation, forming different adsorption complexes on different planes. For this purpose, 12 adsorbate molecules were placed on different surface sites (three molecules on each basal plane and six molecules on different side planes) mimicking adsorption complexes on several adsorption sites which can be described by the scheme:

$$
\left(\mathrm{H}_{2} \mathrm{O}\right)_{270}+12 \mathrm{M} \rightarrow\left(\mathrm{H}_{2} \mathrm{O}\right)_{270} \mathrm{M}_{12}
$$

Here, $\mathrm{M}$ is the glyoxal or its photoproduct molecule in the gas phase, $\left(\mathrm{H}_{2} \mathrm{O}\right)_{270} \mathrm{M}_{12}$ is the adsorption complex of $\mathrm{M}$ at different nanoparticle surface sites. The energy of this reaction $\Delta_{r} E$ allows evaluating the adsorption energy averaged among 12 adsorption sites of different kinds as $E_{\text {ads }}=\Delta_{r} E / 12$. The geometry optimization was performed for the neat cluster $\left(\mathrm{H}_{2} \mathrm{O}\right)_{270}$ and the resulting complex $\left(\mathrm{H}_{2} \mathrm{O}\right)_{270} \mathrm{M}_{12}$. The optimized structures of s-trans-glyoxal adsorption complexes are shown in Figure 5. The obtained average adsorption energies are given in the second column of Table 5 .

We also considered the intrusion of the glyoxal and its photoproducts into the ice nanoparticles, modeling the substitution reaction:

$$
\left(\mathrm{H}_{2} \mathrm{O}\right)_{270}+6 \mathrm{M} \rightarrow\left(\mathrm{H}_{2} \mathrm{O}\right)_{264} \mathrm{M}_{6}+6 \mathrm{H}_{2} \mathrm{O}
$$

Here, $\left(\mathrm{H}_{2} \mathrm{O}\right)_{264} \mathrm{M}_{6}$ is the substitution complex where six water molecules of the subsurface crystal planes are replaced by $\mathrm{M}$. The 

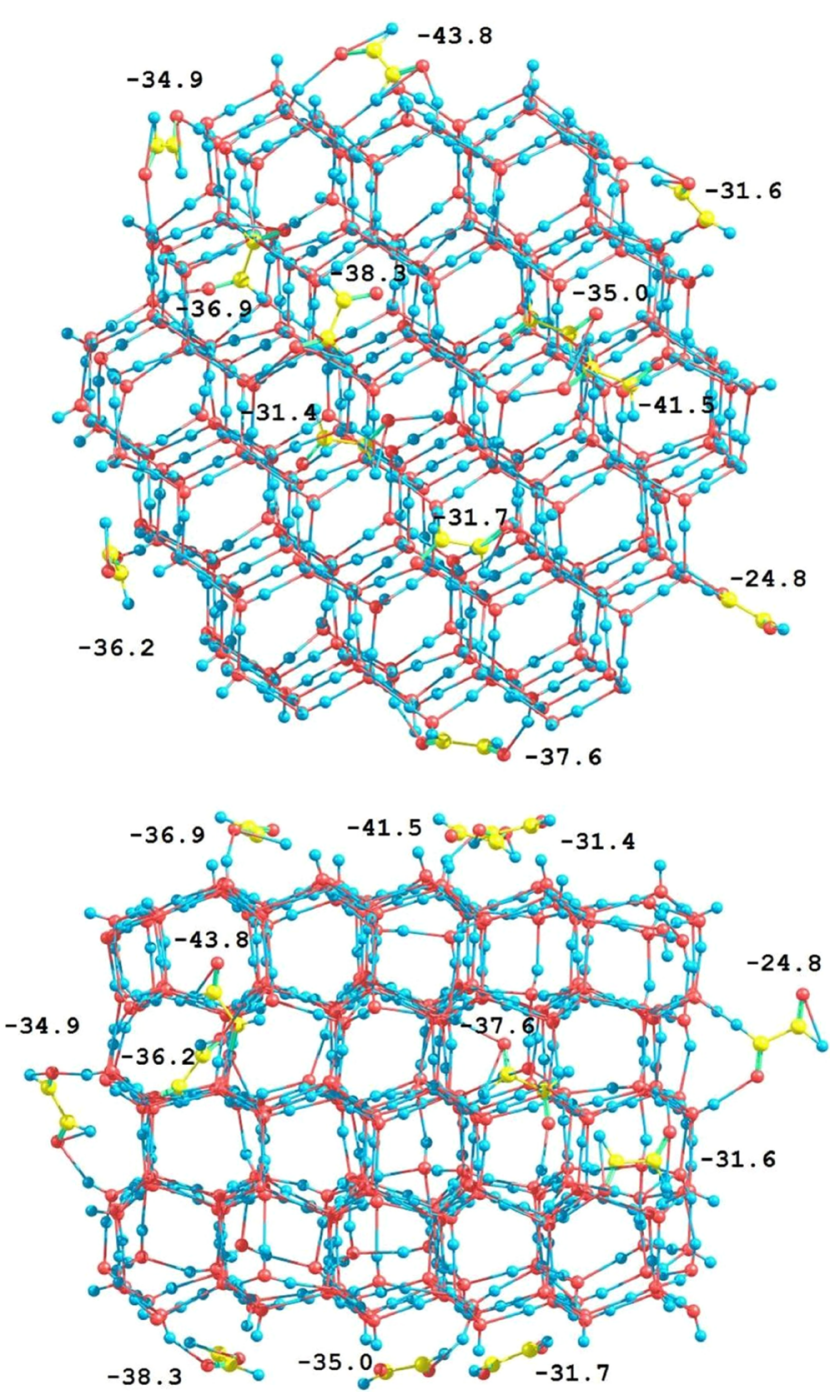

Figure 5. SCC-DFTB+ optimized structure of adsorption complex of 12 molecules of s-trans-glyoxal at various adsorption sites of $\left(\mathrm{H}_{2} \mathrm{O}\right)_{270}$. Upper panel: top view. Bottom panel: side view. Values are the adsorption energies for the given site in $\mathrm{kJ} \mathrm{mol}^{-1}$.

Table 5. SCC-DFTB+ Calculated Adsorption and Substitution Energies ( $\mathrm{kJ} \mathrm{mol}^{-1}$ ) Corresponding to Various Modes of Coordination of Glyoxal Photolysis Products on $\left(\mathrm{H}_{2} \mathrm{O}\right)_{270}{ }^{a}$

$\begin{array}{lcl} & \begin{array}{c}\text { adsorption energy } \Delta E \\ \text { averaged among 12 sites }\end{array} & \begin{array}{c}\text { energy of } \mathrm{H}_{2} \mathrm{O} \text { substitution } \\ \text { averaged among } 6 \text { sites }\end{array} \\ \text { s-cis- }(\mathrm{CHO})_{2} & -44.5 & 42.0(5 \text { trans }+1 \text { cis })(74.6) \\ \text { s-trans- }(\mathrm{CHO})_{2} & -35.3 & 45.2 \\ \mathrm{CH}_{2} \mathrm{O} & -20.3 & 32.0(65.9) \\ \mathrm{H}_{2} \mathrm{O}_{2} & -34.1 & 8.0 \\ s \text {-cis- } \mathrm{HCOOH} & -43.8 & 31.1 \\ \text { s-trans- } \mathrm{HCOOH} & -43.3 & 12.4 \\ \mathrm{CO} & -3.6 & 73.5 \\ \mathrm{CO}_{2} & -14.5 & 56.5\end{array}$

a The values in parentheses are the RI-BLYP/6-31++G(d,p)//RI$\mathrm{BLYP} / 6-31+\mathrm{G}(\mathrm{d})$ calculated energies of $\mathrm{H}_{2} \mathrm{O}$ substitution.

optimized structures of $\left(\mathrm{H}_{2} \mathrm{O}\right)_{264} \mathrm{Gc}_{6}$ ( $\mathrm{Gc}$ stands for s-cis-glyoxal) are shown in Figure 6, and the corresponding energies of reaction 5 are given in third column of Table 5.
The high performance of DFTB method allows switching from the single-site adsorption energy estimation to the exploration of adsorption energy distribution. We calculated the adsorption energy distribution for the $\left(\mathrm{H}_{2} \mathrm{O}\right)_{270} \mathrm{X}_{12}\left(\mathrm{X}=\mathrm{Gt}, \mathrm{CH}_{2} \mathrm{O}\right)$ complexes. Removing the molecules in turn from the optimized $\left(\mathrm{H}_{2} \mathrm{O}\right)_{270} \mathrm{X}_{12}$ structures and making additional optimization for the remaining $\left(\mathrm{H}_{2} \mathrm{O}\right)_{270} \mathrm{X}_{11}$ structure we obtained the single site adsorption energies as an reaction energy of the process:

$$
\left(\mathrm{H}_{2} \mathrm{O}\right)_{270} \mathrm{X}_{11}+\mathrm{X} \rightarrow\left(\mathrm{H}_{2} \mathrm{O}\right)_{270} \mathrm{X}_{12}
$$

To our opinion, the considering of such process instead the single molecule adsorption on different sites is more suitable because it leaves the environment less disturbed and, at the same time, requires lesser time for the optimization of the remaining structure. The obtained single-site adsorption energies in $\mathrm{kJ}$ $\mathrm{mol}^{-1}$ obtained in such a way are given in Figure 5 (values near the glyoxal molecules). Figure 7 shows the histograms for such a distribution obtained for 12 adsorption complexes of s-transglyoxal and $\mathrm{CH}_{2} \mathrm{O}$. As one can see from these histograms, the distribution is rather asymmetric with minimum values (highest adsorption energy) significantly different from the mean values. The average values (given in Table 5) are rather close to the peak positions (highest probability values) for both compounds, and the standard deviations for 12 adsorption energy value of s-transglyoxal are about $5.0 \mathrm{~kJ} \mathrm{~mol}^{-1}$ (compared to the mean value of $-35.3 \mathrm{~kJ} \mathrm{~mol}^{-1}$ ) and only $2.3 \mathrm{~kJ} \mathrm{~mol}^{-1}$ for $\mathrm{CH}_{2} \mathrm{O}$ (mean value $-20.3 \mathrm{~kJ} \mathrm{~mol}^{-1}$ ).

As was mentioned before, we also tried to optimize the adsorption complex of glyoxal with $\left(\mathrm{H}_{2} \mathrm{O}\right)_{270}$ using the modest basis set followed by an energy evaluation in a larger basis, that is, the RI-BLYP/6-311++G(d,p)//RI-BLYP/6-31G+G(d) approach. However, the results of such a composite method in the modest basis set are in poor agreement both with BLYP/6$31++\mathrm{G}(\mathrm{d}, \mathrm{p})$ adsorption energies for the $\left(\mathrm{H}_{2} \mathrm{O}\right)_{72}$ and with DFTB + values obtained for $\left(\mathrm{H}_{2} \mathrm{O}\right)_{270}$ (shown in parentheses in Table 5). This is probably caused by the lack of polarization and diffuse functions in the $6-31+G(d)$ basis set used for the optimization which results in too short hydrogen bond lengths and consequently in unrealistic values of adsorption energies in the following BLYP/6-31++G(d,p) energy calculation. At the same time the results of BLYP/6-31++G $(\mathrm{d}, \mathrm{p})$ for $\left(\mathrm{H}_{2} \mathrm{O}\right)_{72}$ and DFTB for both $\left(\mathrm{H}_{2} \mathrm{O}\right)_{72}$ and $\left(\mathrm{H}_{2} \mathrm{O}\right)_{270}$ give rather similar results for adsorption energies and structural parameters. From this point of view, DFTB on these systems appears more reliable than the pure DFT in smaller bases.

The three most favorable glyoxal adsorption sites were used for the adsorption energy evaluation of $\mathrm{HCO}, \mathrm{HO}$ and $\mathrm{HOO}$ radicals. Because the singlet coupled radical pair is difficult to model with the software available, the adsorption energies were estimated for $\left(\mathrm{H}_{2} \mathrm{O}\right)_{270} \mathrm{R}$ complexes with one radical $\mathrm{R}$ (HCO, $\mathrm{HO}$, or HOO) located on three most favorable sites of the $\left(\mathrm{H}_{2} \mathrm{O}\right)_{270}$ cluster (marked in Figure 5 as $-43.8,-41.5,-38.3$ ). The estimated values of radical adsorption energies are given in Table 6. The maximum adsorption energies of $\mathrm{CHO}$ are significantly lower than the corresponding values for glyoxal. It is also noticeable that the adsorption energies are significantly different for three adsorption sites where the glyoxal molecule is predicted to have similar adsorption affinity. In contrast with $\mathrm{CHO}$, the radicals $\mathrm{HOO}$ and $\mathrm{HO}$ are predicted to have much higher adsorption energies which are only slightly different for three adsorption sites.

Vibrational Frequencies of Adsorbed Species. The calculated vibrational frequencies allow the prediction of IR 

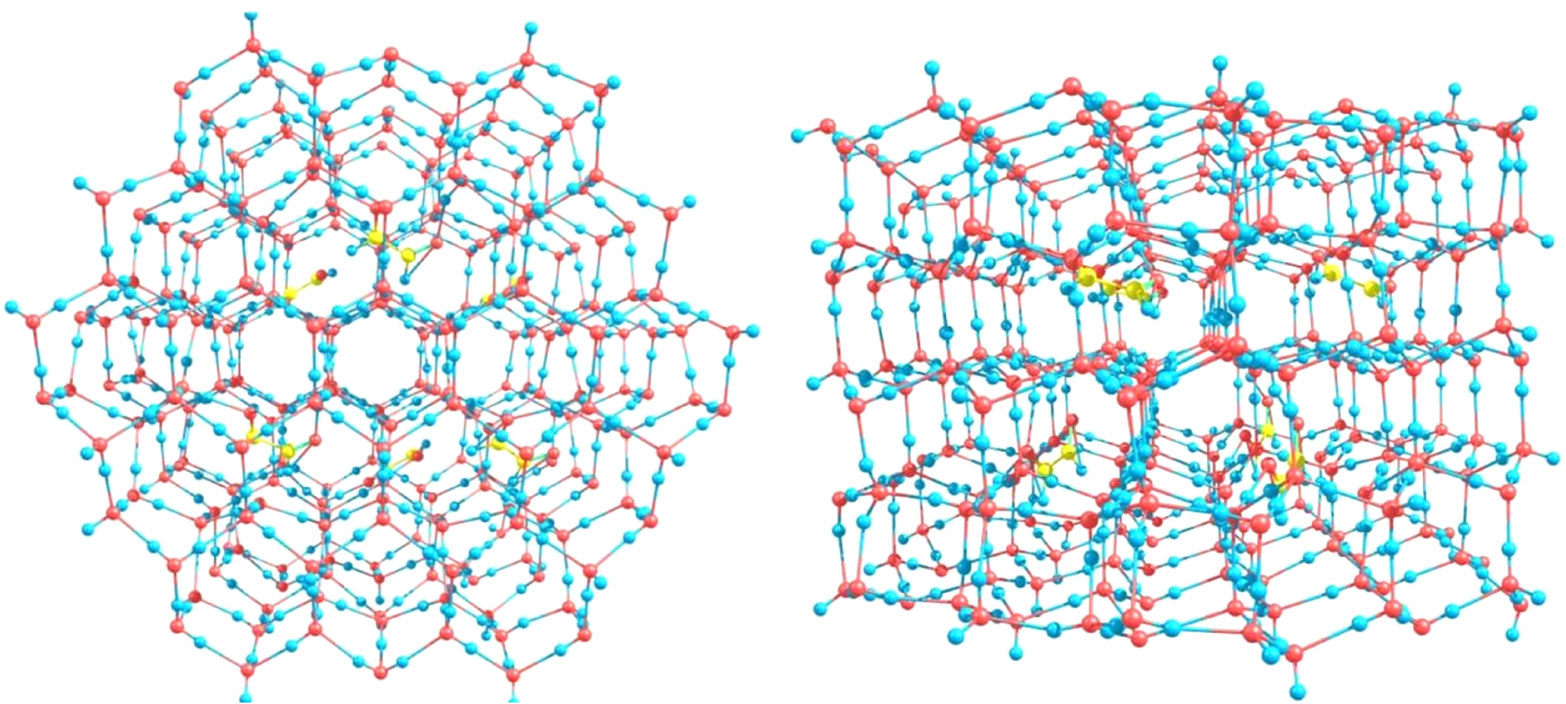

Figure 6. SCC-DFTB+ optimized structure of substitution complex $\left(\mathrm{H}_{2} \mathrm{O}\right)_{264} \mathrm{Gc}_{6}$ formed by six molecules of s-cis-glyoxal and the $\left(\mathrm{H}_{2} \mathrm{O}\right)_{270}$ nanoparticle. Left panel: top view. Right panel: side view.
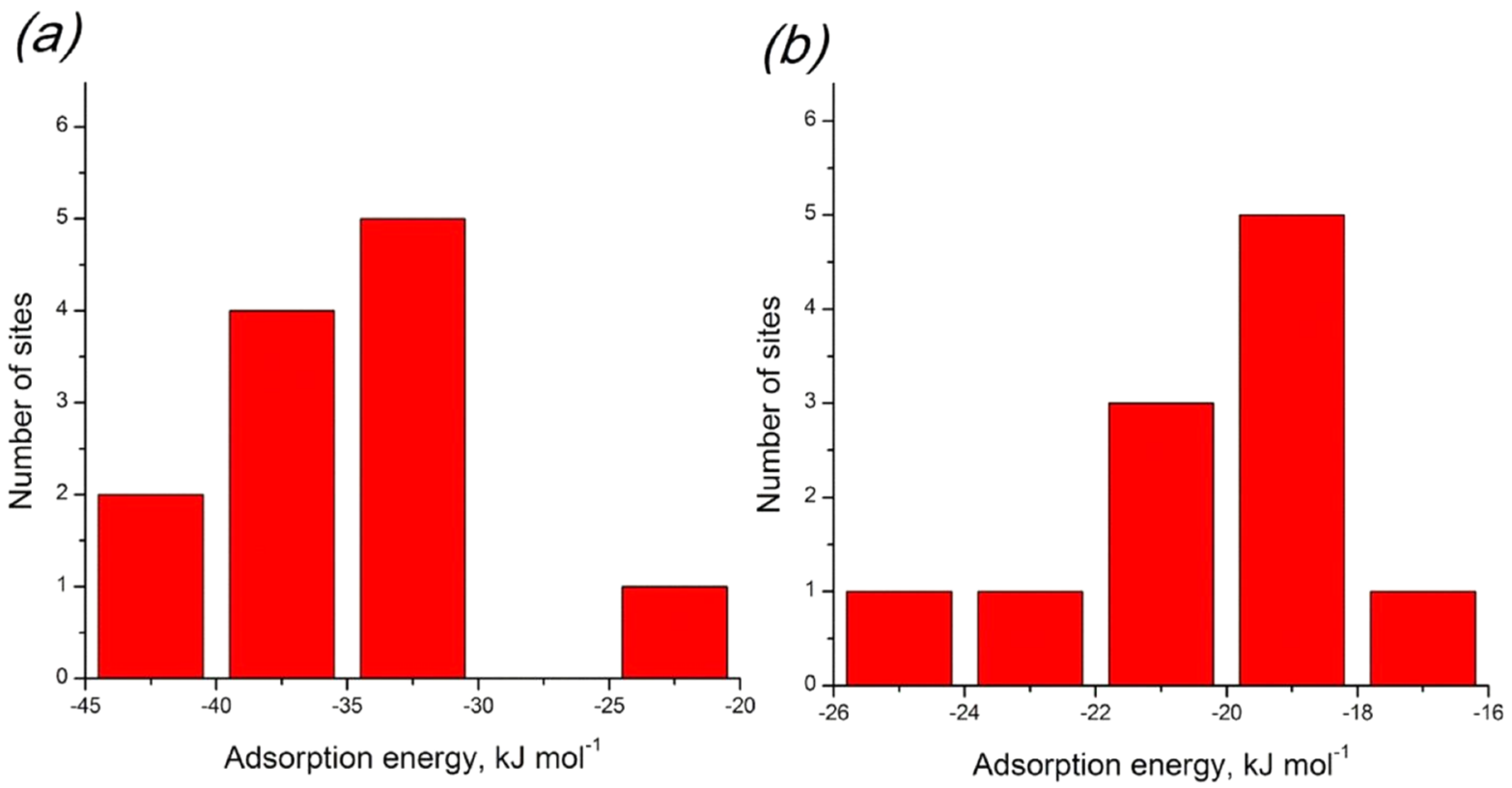

Figure 7. Distribution of binding energies for the adsorption of s-trans-glyoxal (left panel) and $\mathrm{CH}_{2} \mathrm{O}$ (right panel) on 12 different sites of the $\left(\mathrm{H}_{2} \mathrm{O}\right)_{270}$ cluster (results of DFTB+ calculations).

Table 6. SCC-DFTB+ Calculated Adsorption Energies (kJ $\mathrm{mol}^{-1}$ ) Corresponding to Different Modes of Coordination of the CHO, HO, or HOO Radicals on $\left(\mathrm{H}_{2} \mathrm{O}\right)_{270}$

\begin{tabular}{lcc} 
& \multicolumn{2}{c}{ adsorption energy $\Delta E, \mathrm{~kJ} \mathrm{~mol}^{-1}$} \\
\cline { 2 - 3 } radical & basal plane $(2$ sites $)$ & side plane \\
CHO & $-24.0 /-17.7$ & -14.6 \\
HOO & $-48.0 /-44.2$ & -39.3 \\
HO & $-52.2 /-48.6$ & -46.6 \\
\hline
\end{tabular}

spectra of nanoparticles with adsorbed glyoxal molecules and its photoproducts. The simulated spectra are shown in Figure 8. The colored bars indicate the calculated harmonic vibrational frequencies. The envelope of the spectrum is the superposition of Gaussian functions centered at the calculated frequencies with the half-width of $50 \mathrm{~cm}^{-1}$. Because the frequencies were calculated in a harmonic approximation, the scaling factor is typically needed to compare them with the experimentally observed (anharmonic) fundamental frequencies. We elaborated this scaling factor for the BLYP/6-31++G(d,p) level of theory using the gas-phase IR spectra of glyoxal, formaldehyde and water. ${ }^{69}$ However, the best agreement between the calculated and experimental frequencies was achieved with scaling factor close to unity (typically, about 1.002). Therefore, the frequencies presented here are unscaled.

As is shown in Figure 8, the IR spectra of s-trans and s-cisglyoxal molecules is rather significantly distinguishable due to a new band near to $2350 \mathrm{~cm}^{-1}$. Thus, the cis-trans transformation of glyoxal, if it takes place, can be in principle observed in experiment. On the other hand, the calculated IR spectra of adsorbed $\mathrm{HCOOH}$ are quite close to the spectra of s-transglyoxal. This could possibly explain why $\mathrm{HCOOH}$ was not 

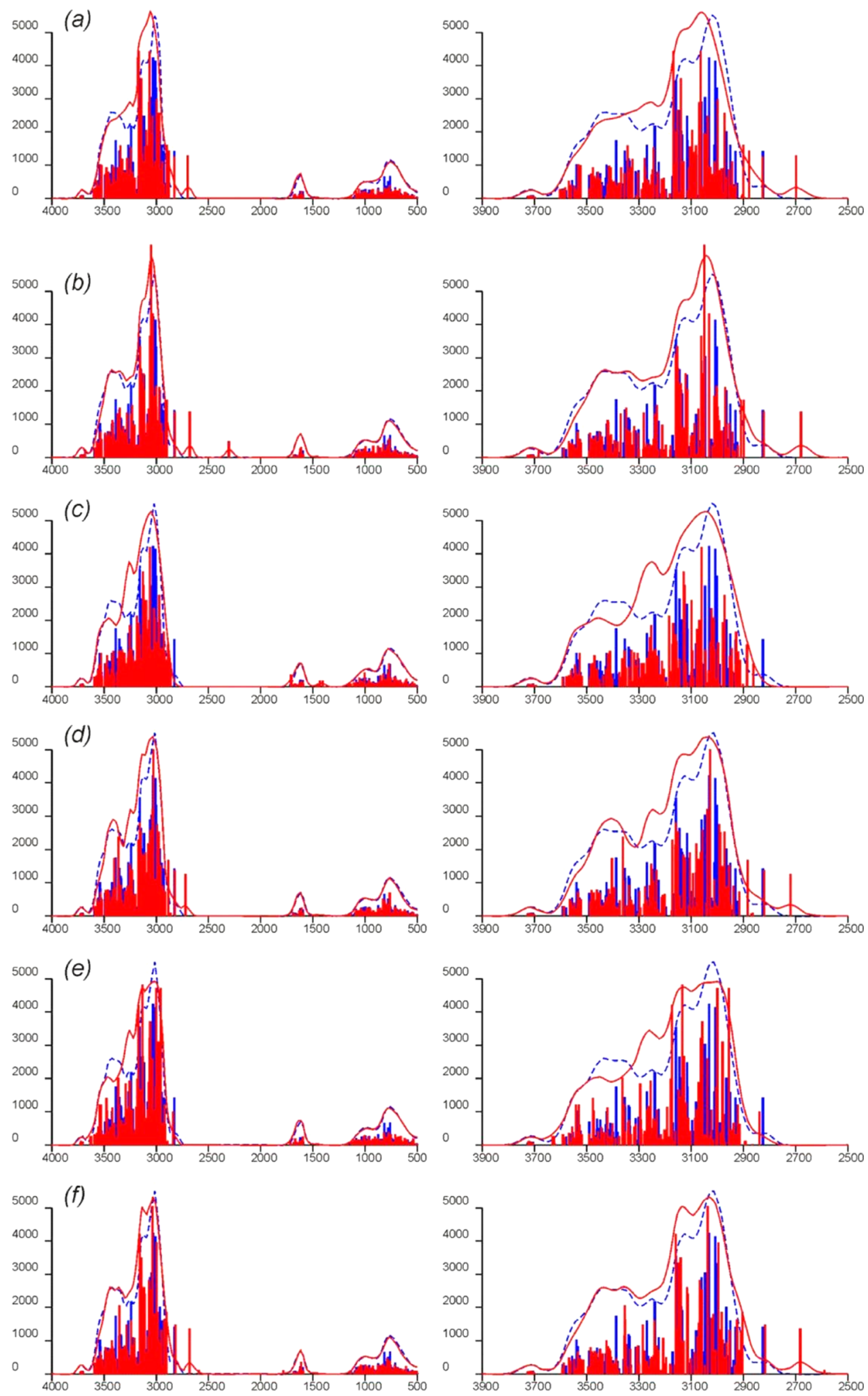

Figure 8. Changes in the calculated ( $\mathrm{BLYP} / 6-31++\mathrm{G}(\mathrm{d}, \mathrm{p})$ IR spectra of $\left(\mathrm{H}_{2} \mathrm{O}\right)_{72}$ ice cluster due to the formation of adsorption complexes: (a) $\left(\mathrm{H}_{2} \mathrm{O}\right)_{72} \mathrm{Gt}_{2} ;(\mathrm{b})\left(\mathrm{H}_{2} \mathrm{O}\right)_{72} \mathrm{Gc}_{2} ;(\mathrm{c})\left(\mathrm{H}_{2} \mathrm{O}\right)_{72}\left(\mathrm{CH}_{2} \mathrm{O}\right)_{2} ;(\mathrm{d})\left(\mathrm{H}_{2} \mathrm{O}\right)_{72}(\mathrm{HCOOH})_{2} ;(\mathrm{e})\left(\mathrm{H}_{2} \mathrm{O}\right)_{72}\left(\mathrm{CO}_{2}\right)_{2} ;(\mathrm{f})\left(\mathrm{H}_{2} \mathrm{O}\right)_{72}$ (HCO). Left panel: common view. Right panel: detalization of $\mathrm{OH}$-absorption band. Horizontal axis: wavenumbers $\left(\mathrm{cm}^{-1}\right)$. Vertical axis: IR intensities $\left(\mathrm{km} \mathrm{mol}^{-1}\right)$. Dashed trace $(\mathrm{blue})$ : source cluster. Solid trace (red): adsorption complex.

identified in the experimental spectra of glyoxal photolyzed on ice films. ${ }^{19}$

The adsorption of other species results in insignificant IR shifts and new bands are not appearing. However, the ice absorption band undergoes rather significant and specific reshaping during the adsorption. This prediction can be helpful in laboratory experiments dealing with the interaction of organic molecules with ice surfaces or ice particles. 


\section{DISCUSSION}

Comparison of DFTBA and DFTB+ with DFT Results. Because DFTB is still not a routine method of quantum chemical studies (see for details the most recent review ${ }^{40}$ and references therein), it was worthwhile to validate its performance comparing its results with the ones of DFT calculations. The comparison of the calculated adsorption energies for the medium-size clusters as well as the structural parameters of large clusters shows that the DFTB (employed here DFTB2) method is quite good for calculations of large systems. The difference between the energy values in $\left(\mathrm{H}_{2} \mathrm{O}\right)_{72}$ was only in the range of $9 \mathrm{~kJ} \mathrm{~mol}^{-1}$ with typical deviations of about 2-4 $\mathrm{kJ} \mathrm{mol}^{-1}$. The DFTB structural parameters show the same features which were found in the DFT calculations. Although the mean values of $\mathrm{O}-\mathrm{H}$ bond lengths in $\left(\mathrm{H}_{2} \mathrm{O}\right)_{72}$ are typically shorter by $0.014 \AA$, the $\mathrm{O} \cdots \mathrm{H}$ bond lengths are elongated by $0.025 \AA$. The bond length distributions in $\left(\mathrm{H}_{2} \mathrm{O}\right)_{72}$ obtained at DFT and DFTB levels are quite similar, especially for the $\mathrm{O}-\mathrm{H}$ bonds. They demonstrate the same clustering into the very short (dangling), short (surface) and long (internal) bond networks. For the radical adsorption energies, the DFTBA calculation gives the results similar to the DFT calculations. At the same time, the structure data calculated at the PM3 level are quite different from the DFT values.

For the medium-size clusters, DFTB calculations give the timings which are typically 50-100 times shorter than the calculations at the DFT level. For the largest clusters considered here DFTB was typically 100-200 times faster. In comparison with the semiempirical PM3 method, DFTBA timing is also 1.52 times better. Thus, DFTB theory is more preferable for the large-scale calculations than the PM3 method (and probably other NDDO-type semiempirical methods ${ }^{70}$ as follows from our previous attempts to use the AM1 method for the ice structure optimization $^{71}$ ) and may be recommended for the quantum chemical studies of water rich systems, in particular, water ices. Although the recent reviews on DFTB make only very cautious appraisals, ${ }^{72}$ we found that the performance of this method on nanoscale water clusters with adsorbed organic molecules is very favorable.

Coordination Modes and Cluster Size Effect. The close inspection of the single-site adsorption energy values (Figure 5) allows one to conclude that there are no specific crystal faces or sites on the nanoparticle which are specifically preferable for the glyoxal coordination. Both the basal and the side faces are approximately equal in their coordination ability, taking into account the differences in the molecular orientation. However, the essential factor of the coordination is the presence of the dangling hydrogens. As it is seen from Figure 5, the coordination is easier (multifold coordination is available and adsorption energies are higher) at the faces where more dangling hydrogens are present. In contrast, at planes and sites with lower density of dangling $\mathrm{H}$ groups, the coordination is less substantial resulting sometimes to the bridge-like 2 -fold coordination structures with lower adsorption energy.

It is interesting to compare directly the results for the calculated adsorption energies obtained at the BLYP/6-31+ $+\mathrm{G}(\mathrm{d}, \mathrm{p})$ for $\left(\mathrm{H}_{2} \mathrm{O}\right)_{72}$ (adsorption on two selected sites of $(0001)$ crystallographic plane of the cluster surface) and DFTB results for the $\left(\mathrm{H}_{2} \mathrm{O}\right)_{270}$ cluster (averaged among 12 sites on different planes) (Table 5). The calculated adsorption energies for different clusters are quite close to each other for glyoxal but rather different for other species. Probably this is due to the different structures of adsorption complexes: for $\left(\mathrm{H}_{2} \mathrm{O}\right)_{72}$. $2 \mathrm{HCOOH}$ only the bridge-like structures of adsorption complexes were obtained whereas for the $\left(\mathrm{H}_{2} \mathrm{O}\right)_{270}$ cluster and, thus, for DFTB computational level the "recumbent" structures dominate and even single coordination of $\mathrm{HCOOH}$ is present. The adsorption energies of other photoproducts are distinguished between two clusters by $6-15 \mathrm{~kJ} \mathrm{~mol}^{-1}$ with the maximum discrepancy in the case of $\mathrm{H}_{2} \mathrm{CO}$ (about $15 \mathrm{~kJ} \mathrm{~mol}^{-1}$ ). This is probably due to the fact that the adsorption of $\mathrm{H}_{2} \mathrm{CO}$ is more favorable at the side planes of the ice crystal whereas in the case of glyoxal the adsorption is almost equally favorable for the side and basal planes. The same situation can be seen for other products although to a lesser extent. The adsorption energies are only slightly different in these cases.

It is also worthwhile to compare the calculated adsorption energies obtained at the DFTBA level for $\left(\mathrm{H}_{2} \mathrm{O}\right)_{72}$ (adsorption on selected site of (0001) crystallographic plane of the cluster surface) and DFTB+ results for the $\left(\mathrm{H}_{2} \mathrm{O}\right)_{270}$ cluster (averaged among 12 sites on different planes). Because the DFTBA and DFTB + approaches are based on the same theory, the differences in calculation results are mostly dependent on the structure of adsorption sites. It is interesting that the calculated adsorption energies are quite close both for glyoxal and all proposed photoproducts except $\mathrm{HCOOH}$. The energy differences are typically in the range of $5 \mathrm{~kJ} \mathrm{~mol}^{-1}$ (Table 5). In the case of $\mathrm{HCOOH}$, the discrepancy is about $15 \mathrm{~kJ} \mathrm{~mol}^{-1}$ which is probably due to the different structure of adsorption complexes on $\left(\mathrm{H}_{2} \mathrm{O}\right)_{72}$ in comparison with $\left(\mathrm{H}_{2} \mathrm{O}\right)_{270}$. Thus, the adsorption abilities of different sites located at different crystal planes are virtually equal and there is no preferable plane for the adsorption. At the same time, we need to mention that this observation is valid for the average values and the separate sites can be significantly differed in their adsorption affinity.

The effect of the crystalline environment can also be estimated by direct comparison between the obtained adsorption enthalpy values and the measured enthalpies of atmospheric molecules on the ice surface. At the moment, the experimental results on the thermodynamics of adsorption of $\mathrm{H}_{2} \mathrm{O}_{2}, \mathrm{CH}_{2} \mathrm{O}, \mathrm{CO}_{2}, \mathrm{HCOOH}$ are available. The enthalpy of $\mathrm{H}_{2} \mathrm{O}_{2}$ adsorption measured in the temperature range $203-233 \mathrm{~K}^{73}$ is $-(32 \pm 5) \mathrm{kJ} \mathrm{mol}^{-1}$, in perfect agreement with the value of $-36.2 \mathrm{~kJ} \mathrm{~mol}^{-1}$ estimated in the present work at the RI-BLYP/6-31++G(d,p) level for $\left(\mathrm{H}_{2} \mathrm{O}\right)_{72}$ at $T=200 \mathrm{~K}$, and with the average adsorption energy of $-34.1 \mathrm{~kJ}$ $\mathrm{mol}^{-1}$ obtained at SCC-DFTB+ for $\left(\mathrm{H}_{2} \mathrm{O}\right)_{270} \cdot 12 \mathrm{H}_{2} \mathrm{O}_{2}$. For the formaldehyde adsorption, the significantly lower adsorption ability to the ice surface was observed in the experimental study in comparison with acetone and methanol. ${ }^{74}$ This made impossible the direct measurement of adsorption enthalpy which was estimated as significantly lower than $-46 \mathrm{~kJ} \mathrm{~mol}^{-1}$ (the value obtained for acetone). In the present work, the formaldehyde adsorption enthalpy is $-27.4 \mathrm{~kJ} \mathrm{~mol}^{-1}$, in agreement with this conclusion and also with the results of previous calculations (binding energy is in range from -19.4 to $-33.7 \mathrm{~kJ} \mathrm{~mol}^{-1}$ at the PHF and HF-GGA theories ${ }^{75}$ ). Then, the reported value ${ }^{76}$ of the adsorption Gibbs free energy for $\mathrm{CH}_{2} \mathrm{O}$ on ice at $T=260 \mathrm{~K}$ estimated in the Monte Carlo simulations was $-11.7 \mathrm{~kJ} \mathrm{~mol}^{-1}$ which is in reasonable agreement with our value $-7.9 \mathrm{~kJ} \mathrm{~mol}^{-1}(T=200 \mathrm{~K})$. For $\mathrm{CO}_{2}$ its activation desorption energy from amorphous $\left(E_{d}=20.7 \pm 2 \mathrm{~kJ} \mathrm{~mol}^{-1}\right)$ and crystalline water ices $\left(E_{d}=19.9 \pm 2 \mathrm{~kJ} \mathrm{~mol}^{-1}\right)^{77}$ is in good agreement with our calculated $\Delta_{\text {ads }} H(0)\left(-17.0 \mathrm{~kJ} \mathrm{~mol}^{-1}\right)$ (cf. Tables 2,3). For the $s$-cis- $\mathrm{HCOOH}$, the estimated value of $\Delta_{\mathrm{ads}} H(200)$ was -51.9 $\mathrm{kJ} / \mathrm{mol}\left(\Delta_{\mathrm{ads}} E=-43.8 \mathrm{~kJ} \mathrm{~mol}^{-1}\right.$ at SCC-DFTB +$)$ which is also in 
a good agreement with the measured values $-(54 \pm 8) \mathrm{kJ} \mathrm{mol}^{-1}$ of Hantal et al. ${ }^{78}$ and $-(51 \pm 4) \mathrm{kJ} \mathrm{mol}^{-1}$ of von Hessberg et al. ${ }^{79}$ (with the adsorption enthalpy of $-54 \mathrm{~kJ} \mathrm{~mol}^{-1}$ estimated for low coverage). The most recent grand canonical Monte Carlo simulation of $\mathrm{HCOOH}$ adsorption with the TIP5P potential at the troposphere relevant conditions provides the binding energy of $-59.8 \mathrm{~kJ} \mathrm{~mol}^{-1}$ for non saturated single layer adsorption while multilayer adsorption is less exothermic (estimated chemical potential is about $\left.-34 \mathrm{~kJ} \mathrm{~mol}^{-1}\right){ }^{80}$ Thus, we conclude that the calculations made for the nanosize clusters are also suitable for the estimation of the adsorption energies at the solid ice, at least under the conditions when the well-defined crystalline ice surface is formed ${ }^{81,82}$ and no association ${ }^{83}$ or dissociation of adsorbed molecules especially of formic acid molecules occurs. ${ }^{84-86}$ The adsorption energy $\left(-43.8 \mathrm{~kJ} \mathrm{~mol}^{-1}\right)$ calculated here with SCC$\mathrm{DFTB}+$ method is reasonable agreement with the value of $-61 \mathrm{~kJ}$ $\mathrm{mol}^{-1}$ obtained by Compoint et al. ${ }^{87}$ in the classical MD simulation using the combination of TIP4P and OPLSA potentials. As one can note, the earlier obtained discrepancy between calculated and measured values (see ibid. and references therein as well as the data collected in ref 33) cannot be elucidated by dissociation of $\mathrm{HCOOH}$ on water ice. Comparison of modern measured values ${ }^{78,79}$ for $\mathrm{HCOOH}$ and quantum chemical based estimation of enthalpy eliminates the controversial. Furthermore, even the data ${ }^{87}$ for adsorption and incorporation on/in ice are very competitive. It is interesting that the results reported in the present study for the incorporation of $\mathrm{HCOOH}$ in rather different energies for the s-cis and s-trans forms (Table 5) as was reproduced in several geometry optimizations from different starting points. The close inspection shows that this difference is approximately equal to the energy difference between the conformations. Thus, it can be interpreted as approximately equipotential interactions of both molecules inside the crystalline matrix (due to the abundant $\mathrm{H}$ bonds around) which result in the significantly higher incorporation energy of the most stable conformer.

Effect of Cluster Environment on the Photolysis Mechanism. As it is evident from the data in Tables 2-4, the effect of cluster environment, although remarkable, should have no significant influence on the relative thermodynamic values of the secondary photolytic reactions listed in Table 1 . The difference in the adsorption energies are typically in ranges 5-15 $\mathrm{kJ} \mathrm{mol}^{-1}$ which provides only a small contribution to typical energies of elementary reactions. However, the effect of cluster environment to the activation energies can be more pronounced. Moreover, the most important factor affecting the reaction kinetics can be high concentration of water in the cluster environment and presence of the oxygen molecules at the cluster surface. For these conditions, the surface of nanoparticles should be enriched with the products of reactions of $\mathrm{CHO}$ radicals with water and oxygen, namely, $\mathrm{CH}_{2} \mathrm{O}, \mathrm{CO}, \mathrm{H}_{2} \mathrm{O}_{2}$. Among them $\mathrm{CH}_{2} \mathrm{O}$ and $\mathrm{CO}$ are the products which are registered earlier in the laboratory experiments of glyoxal photolysis on ice films. However, the close inspections of experimental spectra also show that there are some spectral features at the low-frequency wing of water ice broad IR band in the region of $2800-3000 \mathrm{~cm}^{-1}$. This is the region of the characteristic band of $\mathrm{H}_{2} \mathrm{O}_{2}\left(\mathrm{H}_{2} \mathrm{O}_{2}\right.$ band 2859 $\mathrm{cm}^{-1}$ registered in the spectra of $\mathrm{H}_{2} \mathrm{O}_{2}$ deposited on ice films ${ }^{71}$ ). Thus, it cannot be excluded that $\mathrm{H}_{2} \mathrm{O}_{2}$ formation also takes place during the photolysis of glyoxal adsorbed on the ice film.

\section{CONCLUSIONS}

1 The adsorption of s-trans- and s-cis-glyoxal ( $\mathrm{CHO})_{2}$ molecules and the possible photoproducts of its solar UV photolysis ( $\mathrm{CHO}, \mathrm{CH}_{2} \mathrm{O}, \mathrm{HCOOH}, \mathrm{CO}, \mathrm{CO}_{2}, \mathrm{H}_{2} \mathrm{O}_{2}$ ) on various surface sites of water ice nanoparticles $\left(\mathrm{H}_{2} \mathrm{O}\right)_{48}$, $\left(\mathrm{H}_{2} \mathrm{O}\right)_{72}$, and $\left(\mathrm{H}_{2} \mathrm{O}\right)_{270}$ was studied for the first time using the DFT (BLYP/6-31++G(d,p)) and SCC-DFTB quantum chemical methods. The high effectiveness of SCC-DFTB model allows the full structure optimization of the $\left(\mathrm{H}_{2} \mathrm{O}\right)_{270}$ particle up to $2.5 \mathrm{~nm}$ in diameter along with the variety of adsorption complexes on its surface.

2 The bond length distributions of the $\left(\mathrm{H}_{2} \mathrm{O}\right)_{72}$ nanoparticles obtained with DFT, DFTB, and PM3 methods shows that DFTB results are in better agreement to DFT than the PM3 values. The adsorption energies for the clusters $\left(\mathrm{H}_{2} \mathrm{O}\right)_{48}$ and $\left(\mathrm{H}_{2} \mathrm{O}\right)_{72}$ obtained with DFTB are also in a good agreement with the values calculated at the DFT level.

3 The results obtained with smallest models $\left(\mathrm{H}_{2} \mathrm{O}\right)_{48}$ with fixed boundary atoms are significantly different from those obtained for the $\left(\mathrm{H}_{2} \mathrm{O}\right)_{72}$ and $\left(\mathrm{H}_{2} \mathrm{O}\right)_{270}$ clusters and not suitable for the good estimates of adsorption energies. The adsorption energies and structural parameters of $\left(\mathrm{H}_{2} \mathrm{O}\right)_{72}$ clusters are in a good agreement with the results for $\left(\mathrm{H}_{2} \mathrm{O}\right)_{216}$, and $\left(\mathrm{H}_{2} \mathrm{O}\right)_{270}$ and, thus, $\left(\mathrm{H}_{2} \mathrm{O}\right)_{72}$ is the good model for estimation of these parameters at the DFT level. The calculations of $\left(\mathrm{H}_{2} \mathrm{O}\right)_{270}$ with DFTB, however, allows obtaining not only the single adsorption energy but also their site distributions and the values averaged among several different sites.

4 The adsorption energies of s-trans-glyoxal at the nanoparticle surface estimated with different methods are in range from -24 to $-34 \mathrm{~kJ} \mathrm{~mol}^{-1}$ with the best estimate at the BLYP/6-311++G(2d,2p) level for $\left(\mathrm{H}_{2} \mathrm{O}\right)_{72}$ cluster of $-23.5 \mathrm{~kJ} \mathrm{~mol}^{-1}$. The enthalpy of adsorption is in range from -17 to $-26 \mathrm{~kJ} \mathrm{~mol}^{-1}$ and slightly increases with temperature.

5 The nanoparticle $\left(\mathrm{H}_{2} \mathrm{O}\right)_{270}$ with crystal-like ice structure has no specific faces especially preferable for the glyoxal adsorption. However, the essential factor of better adsorption is the presence on the surface of the dangling hydrogen atoms allowing the multifold coordination and higher adsorption energy.

6 The BLYP/6-31++G(d,p) calculated adsorption enthalpies of the glyoxal UV photolysis products at $\left(\mathrm{H}_{2} \mathrm{O}\right)_{72}$ are -24 to $-27 \mathrm{~kJ} \mathrm{~mol}^{-1}\left(\mathrm{CHO}, \mathrm{CH}_{2} \mathrm{O}\right),-37\left(\mathrm{H}_{2} \mathrm{O}_{2}\right)$, and -12 to $-17\left(\mathrm{CO}, \mathrm{CO}_{2}\right) \mathrm{kJ} \mathrm{mol}^{-1}$. At the DFTB level for $\left(\mathrm{H}_{2} \mathrm{O}\right)_{270}$ the estimated values for $\mathrm{CH}_{2} \mathrm{O}$ and $\mathrm{HCOOH}$ are somewhat different $\left(-20\right.$ and $-44 \mathrm{~kJ} \mathrm{~mol}^{-1}$, respectively). On the basis of the calculated adsorption enthalpies values, we conclude that $\mathrm{H}_{2} \mathrm{O}_{2}$ and $\mathrm{HCOOH}$ will be accumulated in the ice particles during the photolysis, $\mathrm{CO}$ and $\mathrm{CO}_{2}$ will desorb, and $\mathrm{CH}_{2} \mathrm{O}$ will be distributed between the gas phase and ice particles similarly to glyoxal.

\section{ASSOCIATED CONTENT}

\section{Supporting Information}

Optimized Cartesian coordinates for source water clusters $\left(\mathrm{H}_{2} \mathrm{O}\right)_{n}, n=48,72,270$, and the adsorption complexes $\left(\mathrm{H}_{2} \mathrm{O}\right)_{n} \mathrm{M}_{k}(\mathrm{M}=$ molecule of glyoxal and its photoproducts). 
This material is available free of charge via the Internet at http:// pubs.acs.org.

\section{AUTHOR INFORMATION}

\section{Corresponding Author}

*(S.K.I.) E-mail: ignatov@ichem.unn.ru.

\section{Notes}

The authors declare no competing financial interest.

\section{ACKNOWLEDGMENTS}

This work was supported in part by the U.S. National Science Foundation (CHE-0832622). O.B.G. and A.E.M. acknowledge the use of computational resources at The Stokes Advanced Research Computing Center, University of Central Florida (UCF), and the National Energy Research Scientific Computing Center, which is supported by the Office of Science of the U.S. Department of Energy under Contract No. DE-AC0205CH11231. S.K.I. and A.G.R. acknowledge the RFBR Project 11-03-00085. S.K.I. and O.B.G. are thankful to DAAD, the International Office of the University of Bremen, and the Alfred Wegener Institute for the fellowship support. O.B.G. is grateful to Dr. Dimitri N. Laikov (Chemistry Department, Moscow State University, Russia) for providing the PRIRODA 13 program and Dr. Alexander M. Genaev (N. N. Vorozhtsov Novosibirsk Institute Of Organic Chemistry, Siberian Branch of Russian Academy of Sciences, Russia) for providing the basis set library for the PRIRODA program.

\section{REFERENCES}

(1) Devlin, J. P.; Buch, V. Ice Nanoparticles and Ice Adsorbate Interactions: FTIR Spectroscopy and Computer Simulations. In Water in Confining Geometries; Buch, V., Devlin, J. P., Eds.; Springer-Verlag: Berlin, Germany, 2003; pp 425-462.

(2) Watanabe, N.; Kouchi, A. Ice surface reactions: A key to chemical evolution in space. Prog. Surf. Sci. 2008, 83, 439-489.

(3) Park, J.-Y.; Woon, D. E. Theoretical Modeling of Formic Acid $(\mathrm{HCOOH})$, Formate $\left(\mathrm{HCOO}^{-}\right)$, and Ammonium $\left(\mathrm{NH}_{4}^{+}\right)$Vibrational Spectra in Astrophysical Ices. Astrophys. J. 2006, 648, 1285-1290.

(4) Woon, D. E. Ab Initio Quantum Chemical Studies of Reactions in Astrophysical Ices - Reactions Involving $\mathrm{CH}_{3} \mathrm{OH}, \mathrm{CO}_{2}, \mathrm{CO}$, and $\mathrm{HNCO}$ in $\mathrm{H}_{2} \mathrm{CO} / \mathrm{NH}_{3} / \mathrm{H}_{2} \mathrm{O}$ Ices. AIP Conf. Proc. 2006, 855, 305-314.

(5) Krim, L.; Lasne, J.; Laffon, C.; Parent, P. Influence of Water in the UV-Induced Chemistry of Methanol in the Solid Phase. J. Phys. Chem. A 2009, 113, 8979-8984.

(6) Chris, J. B.; Tetsuya, H.; Yong Seol, K.; Masahiro, K.; Ralf, I. K. Laboratory Studies on the Formation of Formic Acid ( $\mathrm{HCOOH})$ in Interstellar and Cometary Ices. Astrophys. J. 2011, 727, 27.

(7) Tadić, J.; Moortgat, G. K.; Wirtz, K. Photolysis of glyoxal in air. J. Photochem. Photobiol. A 2006, 1977, 116-124.

(8) Zhu, L.; Kellis, D.; Ding, C.-F. Photolysis of glyoxal at 193, 248, 308 and $351 \mathrm{~nm}$. Chem. Phys. Lett. 1996, 257, 487-491.

(9) Langford, A. O.; Moore, C. B. Reaction and relaxation of vibrationally excited formyl radicals. J. Chem. Phys. 1984, 80, 42044210.

(10) Chen, Y.; Zhu, L. Wavelength-Dependent Photolysis of Glyoxal in the 290-420 nm Region. J. Phys. Chem. A 2003, 107, 4643-4651.

(11) Feierabend, K. J.; Flad, J. E.; Brown, S. S.; Burkholder, J. B. HCO Quantum Yields in the Photolysis of $\mathrm{HC}(\mathrm{O}) \mathrm{C}(\mathrm{O}) \mathrm{H}$ (Glyoxal) between 290 and $420 \mathrm{~nm}$. J. Phys. Chem. A 2009, 113, 7784-7794.

(12) Salter, R. J.; Blitz, M. A.; Heard, D. E.; Pilling, M. J.; Seakins, P. W. New Chemical Source of the HCO Radical Following Photoexcitation of Glyoxal, (HCO) $)_{2}$. J. Phys. Chem. A 2009, 113, 8278-8285.

(13) Koch, D. M.; Khieu, N. H.; Peslherbe, G. H. Ab Initio Studies of the Glyoxal Unimolecular Dissociation Pathways. J. Phys. Chem. A 2001, 105, 3598-3604.
(14) Li, X.; Millam, J. M.; Schlegel, H. B. Glyoxal photodissociation. An ab initio direct classical trajectory study of $\mathrm{C}_{2} \mathrm{H}_{2} \mathrm{O}_{2} \rightarrow \mathrm{H}_{2}+2 \mathrm{CO}$. J. Chem. Phys. 2001, 114, 8897-8904.

(15) Li, X.; Millam, J. M.; Schlegel, H. B. Glyoxal photodissociation. II. An ab initio direct classical trajectory study of $\mathrm{C}_{2} \mathrm{H}_{2} \mathrm{O}_{2} \rightarrow \mathrm{CO}+\mathrm{H}_{2}$ CO. J. Chem. Phys. 2001, 115, 6907-6912.

(16) Dobeck, L. M.; Lambert, H. M.; Kong, W.; Pisano, P. J.; Houston, P. L. $\mathrm{H}_{2}$ Production in the 440-nm Photodissociation of Glyoxal. J. Phys. Chem. A 1999, 103, 10312-10323.

(17) Roscoe, J. M.; Back, R. A. Product ratios in the photolysis of cisand trans-glyoxal at low pressures: the mechanisms of the thermal and the photochemical decompositions. J. Phys. Chem. 1986, 90, 598-602.

(18) Atkinson, R. Atmospheric chemistry of VOCs and $\mathrm{NO}_{\mathrm{x}}$. Atmos. Environ. 2000, 34, 2063-2101.

(19) Manohar, S. N. FTIR Spectroscopic Studies of Atmospheric Molecules in Ice and on Ice Surfaces; Bremen University: Bremen, Germany, 2008.

(20) Perri, M. J.; Seitzinger, S.; Turpin, B. J. Secondary organic aerosol production from aqueous photooxidation of glycolaldehyde: Laboratory experiments. Atmos. Environ. 2009, 43, 1487-1497.

(21) Carlton, A. G.; Turpin, B. J.; Altieri, K. E.; Seitzinger, S.; Reff, A.; Lim, H.-J.; Ervens, B. Atmospheric oxalic acid and SOA production from glyoxal: Results of aqueous photooxidation experiments. Atmos. Environ. 2007, 41, 7588-7602.

(22) De Haan, D. O.; Corrigan, A. L.; Tolbert, M. A.; Jimenez, J. L.; Wood, S. E.; Turley, J. J. Secondary Organic Aerosol Formation by SelfReactions of Methylglyoxal and Glyoxal in Evaporating Droplets. Environ. Sci. Technol. 2009, 43, 8184-8190.

(23) Ignatov, S. K.; Gadzhiev, O. B.; Kulikov, M. Y.; Petrov, A. I.; Razuvaev, A. G.; Gand, M.; Feigin, A. M.; Schrems, O. Adsorption of Methyl Hydroperoxide $\left(\mathrm{CH}_{3} \mathrm{OOH}\right)$ on Water Ice. Theoretical Study with Systematic Assessment of Coordination Modes. J. Phys. Chem. C 2011, 115, 9081-9089.

(24) Johnston, J. C.; Molinero, V. Crystallization, melting, and structure of water nanoparticles at atmospherically relevant temperatures. J. Am. Chem. Soc. 2012, 134, 6650-6659.

(25) Torchet, G.; Schwartz, P.; Farges, J.; de Feraudy, M. F.; Raoult, B. Structure of solid water clusters formed in a free jet expansion. J. Chem. Phys. 1983, 79, 6196-6202.

(26) Torchet, G.; Farges, J.; de Feraudy, M. F.; Raoult, B. Structural study of $\mathrm{CH}_{4}, \mathrm{CO}_{2}$ and $\mathrm{H}_{2} \mathrm{O}$ clusters containing from several tens to several thousands of molecules. Ann. Phys. Fr. 1989, 14, 245-260.

(27) Buch, V.; Sigurd, B.; Paul Devlin, J.; Buck, U.; Kazimirski, J. K. Solid water clusters in the size range of tens-thousands of $\mathrm{H}_{2} \mathrm{O}$ : a combined computational/spectroscopic outlook. Int. Rev. Phys. Chem. 2004, 23, 375-433.

(28) Pisani, C.; Casassa, S.; Ugliengo, P. Proton-ordered ice structures at zero pressure. A quantum-mechanical investigation. Chem. Phys. Lett. 1996, 253, 201-208.

(29) Casassa, S.; Ugliengo, P.; Pisani, C. Proton-ordered models of ordinary ice for quantum-mechanical studies. J. Phys. Chem. 1997, 106, 8030-8040.

(30) Marinelli, F.; Allouche, A. An ab initio study of acetone and formaldehyde monolayers adsorbed on ice. Chem. Phys. 2001, 272, 137-147.

(31) Devlin, J. P.; Joyce, C.; Buch, V. Infrared Spectra and Structures of Large Water Clusters. J. Phys. Chem. A 2000, 104, 1974-1977.

(32) Sadlej, J.; Buch, V.; Kazimirski, J. K.; Buck, U. Theoretical Study of Structure and Spectra of Cage Clusters $\left(\mathrm{H}_{2} \mathrm{O}\right)_{\mathrm{n}}, \mathrm{n}=7-10$. J. Phys. Chem. A 1999, 103, 4933-4947.

(33) Shoaib, M. A.; Choi, C. H. Adsorptions of Formic and Acetic Acids on Ice Surface: Surface Binding Configurations and a Possibility of Interfacial Proton Transfer. J. Phys. Chem. C 2013, 117, 4181-4188.

(34) Laikov, D. N. Fast evaluation of density functional exchangecorrelation terms using the expansion of the electron density in auxiliary basis sets. Chem. Phys. Lett. 1997, 281, 151-156.

(35) Laikov, D. N. Neglect of four- and approximation of one-, two-, and three-center two-electron integrals in a symmetrically orthogonalized basis. J. Comput. Chem. 2007, 28, 698-702. 
(36) Laikov, D. N.; Ustynyuk, Y. A. PRIRODA-04: a quantumchemical program suite. New possibilities in the study of molecular systems with the application of parallel computing. Russ. Chem. Bull. 2005, 54, 820-826.

(37) Laikov, D. N. PRIRODA13 - A quantum-chemical program suite designed for the study of complex molecular systems by the density functional theory and ab-initio methods.

(38) Laikov, D. N. Development of economical approach for molecular computations by density functional method and its application for solution of sophisticated chemical tasks (in Russian). Ph.D. Thesis. Moscow State Unversity: Moscow, Russia, 2004.

(39) Seifert, G.; Joswig, J.-O. Density-functional tight binding-an approximate density-functional theory method. Wiley Interdiscip. Rev.: Comput. Mol. Sci. 2012, 2, 456-465.

(40) Gaus, M.; Cui, Q.; Elstner, M. Density functional tight binding: application to organic and biological molecules. Wiley Interdiscip. Rev.: Comput. Mol. Sci. 2013, 4, 49-61.

(41) Zheng, G.; Witek, H. A.; Bobadova-Parvanova, P.; Irle, S.; Musaev, D. G.; Prabhakar, R.; Morokuma, K.; Lundberg, M.; Elstner, M.; Köhler, C.; Frauenheim, T. Parameter Calibration of TransitionMetal Elements for the Spin-Polarized Self-Consistent-Charge DensityFunctional Tight-Binding (DFTB) Method: Sc, Ti, Fe, Co, and Ni. J. Chem. Theory Comput. 2007, 3, 1349-1367.

(42) Elstner, M.; Porezag, D.; Jungnickel, G.; Elsner, J.; Haugk, M.; Frauenheim, T.; Suhai, S.; Seifert, G. Self-consistent-charge densityfunctional tight-binding method for simulations of complex materials properties. Phys. Rev. B 1998, 58, 7260-7268.

(43) Porezag, D.; Frauenheim, T.; Köhler, T.; Seifert, G.; Kaschner, R. Construction of tight-binding-like potentials on the basis of densityfunctional theory: Application to carbon. Phys. Rev. B 1995, 51, 1294712957.

(44) File repository for mio perameters data set is http://www.dftb.org (accessed Juny 28th, 2013).

(45) Elstner, M. SCC-DFTB: What Is the Proper Degree of SelfConsistency? J. Phys. Chem. A 2007, 111, 5614-5621.

(46) File repository for mio parameters data set is http://www.dftb.org (accessed Juny 28th, 2013).

(47) Aradi, B.; Hourahine, B.; Frauenheim, T. DFTB+, a Sparse Matrix-Based Implementation of the DFTB Method. J. Phys. Chem. A 2007, 111, 5678-5684.

(48) Köhler, C.; Seifert, G.; Frauenheim, T. Density functional based calculations for $\mathrm{Fe}_{\mathrm{n}}(\mathrm{n} \leqslant 32)$. Chem. Phys. 2005, 309, 23-31.

(49) Köhler, C.; Berücksichtigung von Spinpolarisationseffekten in einem dichtefunktionalbasierten Ansatz (in German). Ph.D. Thesis. Department Physik der Fakultät fur Naturwissenschaften an der Universität Paderborn: Paderborn, Germany, 2003. http://ubdata.uni-paderborn. de/ediss/06/2004/koehler/ (accessed Juny 28th, 2013).

(50) Curtiss, L. A.; Raghavachari, K.; Redfern, P. C.; Rassolov, V.; Pople, J. A. Gaussian-3 (G3) theory for molecules containing first and second-row atoms. J. Chem. Phys. 1998, 109, 7764-7776.

(51) Stanton, J. F.; Gauss, J.; Harding, M. E.; Szalay, P. G.; Auer, A. A.; Bartlett, R. J., Benedikt, U.; Berger, C.; Bernholdt, D. E.; Bomble, Y. J. et al. CFOUR, (Coupled-Cluster techniques for Computational Chemistry). For the current version, see http://www.cfour.de (accessed Juny 28th, 2013).

(52) Frisch, M. J.; Trucks, G. W.; Schlegel, H. B.; Scuseria, G. E.; Robb, M. A.; Cheeseman, J. R.; Montgomery Jr., J. A.; Vreven, T.; Kudin, K. N.; Burant, J. C. et al. Gaussian 03, Revision D.02; Gaussian, Inc.: Wallingford, CT, 2007.

(53) Frisch, M. J.; Trucks, G. W.; Schlegel, H. B.; Scuseria, G. E.; Robb, M. A.; Cheeseman, J. R.; Scalmani, G.; Barone, V.; Mennucci, B.; Petersson, G. A. et al. Gaussian 09, Revision B.2, Gaussian, Inc.: Wallingford, CT, 2010.

(54) Ignatov, S. K. MOLTRAN: A program for molecular visualization and thermodynamic calculations; N.I. Lobachevsky State University of Nizhny Novgorod: Nizhny Novgorod, Russia, 2009. http://www.unn. $\mathrm{ru} / \mathrm{chem} /$ moltran/ (accessed Juny 28th, 2013).

(55) Zhurko, G. Chemcraft, Version 1.7 (build 365), http://www. chemcraftprog.com (accessed Juny 29th, 2013).
(56) Gadzhiev, O. B., II All-Russian Conference of Young Scientists "Progress Of Chemical Physics" (in Russian), ISBN 978-5-94691-544-1, 2013.

(57) Cao, Q.; Berski, S. A.; Rasanen, M.; Latajka, Z.; Khriachtchev, L. Spectroscopic and Computational Characterization of the $\mathrm{HCO} \cdots \mathrm{H}_{2} \mathrm{O}$ Complex. J. Phys. Chem. A 2013, 117, 4385-4393.

(58) Peters, P. S.; Duflot, D.; Faure, A.; Kahane, C.; Ceccarelli, C.; Wiesenfeld, L.; Toubine, C. Theoretical Investigation of the Isomerization of trans- $\mathrm{HCOH}$ to $\mathrm{H}_{2} \mathrm{CO}$ : An Example of a Water-Catalyzed Reaction. J. Phys. Chem. A 2011, 115, 8983-8989.

(59) Masunov, A. E.; Mikhailov, I. A. Theory and computations of twophoton absorbing photochromic chromophores. Eur. J. Chem. 2010, 1, $142-161$.

(60) Mikhailov, I. A.; Belfield, K. D.; Masunov, A. E. DFT-Based Methods in the Design of Two-Photon Operated Molecular Switches. J. Phys. Chem. A 2009, 113, 7080-7089.

(61) Gadzhiev, O. B.; Ignatov, S. K.; Razuvaev, A. G.; Masunov, A. E. Quantum Chemical Study of Trimolecular Reaction Mechanism between Nitric Oxide and Oxygen in the Gas Phase. J. Phys. Chem. A 2009, 113, 9092-9101.

(62) Gadzhiev, O. B.; Ignatov, S. K.; Gangopadhyay, S.; Masunov, A. E.; Petrov, A. I. Mechanism of Nitric Oxide Oxidation Reaction (2NO $+\mathrm{O}_{2} \rightarrow 2 \mathrm{NO}_{2}$ ) Revisited. J. Chem. Theory Comput. 2011, 7 (7), 20212024.

(63) Patel, P. D.; Mikhailov, I. A.; Belfield, K. D.; Masunov, A. E. Theoretical Study of Photochromic Compounds, Part 2: Thermal Mechanism for Byproduct Formation and Fatigue Resistance of Diarylethenes Used as Data Storage Materials. Int. J. Quantum Chem. 2009, 109, 3711-3722.

(64) Atkinson, R.; Baulch, D. L.; Cox, R. A.; Crowley, J. N.; Hampson, R. F.; Hynes, R. G.; Jenkin, M. E.; Rossi, M. J.; Troe, J. Evaluated kinetic and photochemical data for atmospheric chemistry: Volume I - gas phase reactions of $\mathrm{O}_{x}, \mathrm{HO}_{x}, \mathrm{NO}_{\mathrm{x}}$ and $\mathrm{SO}_{\mathrm{x}}$ species. Atmos. Chem. Phys. 2004, No. 4, 1461-1738.

(65) Bozzelli, J. W.; Dean, A. M. Hydrocarbon radical reactions with oxygen: comparison of allyl, formyl, and vinyl to ethyl. J. Phys. Chem. 1993, 97, 4427-4441.

(66) Masunov, A.; Dannenberg, J. J. Theoretical study of urea and thiourea. 2. Chains and ribbons. J. Phys. Chem. B 2000, 104, 806-810.

(67) Cardenas-Jiron, G. I.; Masunov, A.; Dannenberg, J. J. Molecular orbital study of crystalline p-benzoquinone. J. Phys. Chem. A 1999, 103, $7042-7046$.

(68) Boys, S. F.; Bernardi, F. The calculation of small molecular interactions by the differences of separate total energies. Some procedures with reduced errors. Mol. Phys. 1970, 19, 553-567.

(69) Jacox, M. E. Vibrational and Electronic Energy Levels of Polyatomic Transient Molecules. In NIST Chemistry WebBook; Linstrom, P. J., Mallard, W. G., Eds.; NIST Standard Reference Database Number 69; National Institute of Standards and Technology: Gaithersburg MD, 2001.

(70) Otte, N.; Scholten, M.; Thiel, W. Looking at Self-ConsistentCharge Density Functional Tight Binding from a Semiempirical Perspective. J. Phys. Chem. A 2007, 111, 5751-5755.

(71) Ignatov, S. K.; Sennikov, P. G.; Jacobi, H.-W.; Razuvaev, A. G.; Schrems, O. Surface species formed during UV photolysis of ozone adsorbed on water ice films at $80 \mathrm{~K}$. A combined RA-FTIR and DFT study. Phys. Chem. Chem. Phys. 2003, 5, 496-505.

(72) Maupin, C. M.; Aradi, B. 1.; Voth, G. A. The Self-Consistent Charge Density Functional Tight Binding Method Applied to Liquid Water and the Hydrated Excess Proton: Benchmark Simulations. J. Phys. Chem. B 2010, 114, 6922-6931.

(73) Pouvesle, N.; Kippenberger, M.; Schuster, G.; Crowley, J. N. The interaction of $\mathrm{H}_{2} \mathrm{O}_{2}$ with ice surfaces between 203 and $233 \mathrm{~K}$. Phys. Chem. Chem. Phys. 2010, 12, 15544-15550.

(74) Winkler, A. K.; Holmes, N. S.; Crowley, J. N. Interaction of methanol, acetone and formaldehyde with ice surfaces between 198 and 223 K. Phys. Chem. Chem. Phys. 2002, 4, 5270-5275. 
(75) Marinelli, F.; Allouche, A. An ab initio study of acetone and formaldehyde monolayers adsorbed on ice. Chem. Phys. 2001, 272, 137-147.

(76) Pártay, L. B.; Jedlovszky, P.; Hoang, P. N. M.; Picaud, S.; Mezei, M. Free-Energy Profile of Small Solute Molecules at the Free Surfaces of Water and Ice, as Determined by Cavity Insertion Widom Calculations. J. Phys. Chem. C 2007, 111, 9407-9416.

(77) Gálvez, O.; Ortega, I. K.; Maté, B.; Moreno, M. A.; MartínLlorente, B.; Herrero, V. J.; Escribano, R.; Gutiérrez, P. J. A study of the interaction of $\mathrm{CO}_{2}$ with water ice. Astron. Astrophys. 2007, 472, 691698.

(78) Hantal, G.; Jedlovszky, P.; Hoang, P. N. M.; Picaud, S. Investigation of the adsorption behaviour of acetone at the surface of ice. A grand canonical Monte Carlo simulation study. Phys. Chem. Chem. Phys. 2008, 10, 6369-6380.

(79) von Hessberg, P.; Pouvesle, N.; Winkler, A. K.; Schuster, G.; Crowley, J. N. Interaction of formic and acetic acid with ice surfaces between 187 and $227 \mathrm{~K}$. Investigation of single species- and competitive adsorption. Phys. Chem. Chem. Phys. 2008, 10, 2345-2355.

(80) Jedlovszky, P.; Hantal, G.; Neuróhr, K.; Picaud, S.; Hoang, P. N. M.; von Hessberg, P.; Crowley, J. N. Adsorption Isotherm of Formic Acid on the Surface of Ice, as Seen from Experiments and Grand Canonical Monte Carlo Simulation. J. Phys. Chem. C 2008, 112, 89768987.

(81) Bahr, S.; Borodin, A.; Höfft, O.; Kempter, V.; Allouche, A. Interaction of formic acid with solid water. J. Chem. Phys. 2005, 122, 234704-01-234704-05.

(82) Noble, J. A.; Theule, P.; Mispelaer, F.; Duvernay, F.; Danger, G.; Congiu, E.; Dulieu, F.; Chiavassa, T. The desorption of $\mathrm{H}_{2} \mathrm{CO}$ from interstellar grains analogues. Astron. Astrophys. 2012, 543, A5-1-A5-9.

(83) Darvas, M.; Lasne, J.; Laffon, C.; Parent, P.; Picaud, S.; Jedlovszky, P. Adsorption of Acetaldehyde on Ice As Seen from Computer Simulation and Infrared Spectroscopy Measurements. Langmuir 2012, 28, 4198-4207.

(84) Cyriac, J.; Pradeep, T. Structural transformation in formic acid on ultra cold ice surfaces. Chem. Phys. Lett. 2005, 402, 116-120.

(85) Kondo, M.; Shibata, T.; Kawanowa, H.; Gotoh, Y.; Souda, R. TOF-SIMS investigation of hydration of acetic acid adsorbed on amorphous water-ice surface. Nucl. Instrum. Methods Phys. Res., Sect. B 2005, 232, 134-139.

(86) Hellebust, S.; O’Riordan, B.; Sodeau, J. Cirrus cloud mimics in the laboratory: An infrared spectroscopy study of thin films of mixed ice of water with organic acids and ammonia. J. Chem. Phys. 2007, 126, 084702-01-084702-12.

(87) Compoint, M.; Toubin, C.; Picaud, S.; Hoang, P. N. M.; Girardet, C. Geometry and dynamics of formic and acetic acids adsorbed on ice. Chem. Phys. Lett. 2002, 365, 1-7. 